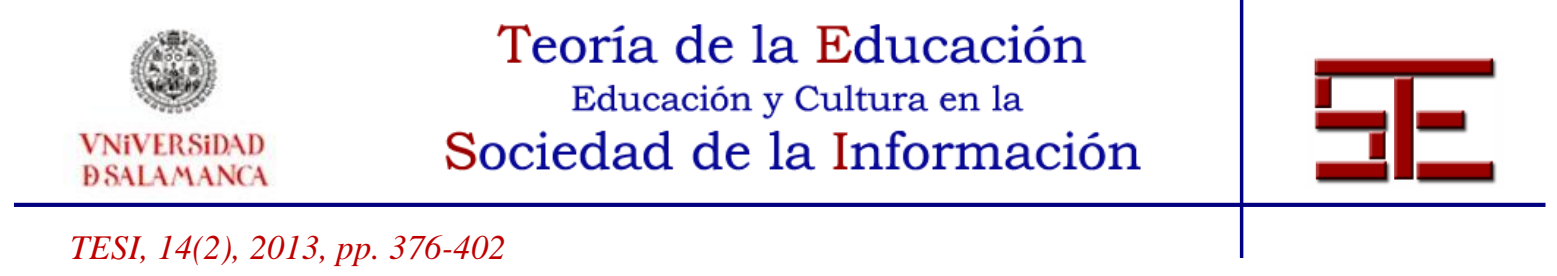

\title{
UNIDADES DE APRENDIZAJE ACTIVAS INTERRELACIONADAS CON USO NATURAL DE HERRAMIENTAS TIC EN LA CONSTRUCCIÓN ARQUITECTÓNICA.
}

Resumen: La incorporación de nuevas tecnologías en los estudios universitarios es un factor consumado. No obstante, no siempre es un proceso realizado correctamente y en muchos casos se ignora la opinión del usuario final, el alumno. Una correcta implementación debe evaluar el grado de satisfacción, necesidad, interés y posibles modificaciones que el uso de cualquier tecnología conlleva tanto en la formación del estudiante como en la percepción de la utilidad y aprovechamiento que este consigue. En el presente artículo analizamos una nueva aproximación en la docencia relacionada con la materia de Construcción Arquitectónica. A partir de una serie de unidades interactivas fundamentadas en el trabajo colaborativo de los alumnos, se abordan problemas complejos próximos a la realidad profesional del sector. El objetivo es valorar el grado de adaptación del alumno a un modelo de aprendizaje centrado en el descubrimiento práctico-teórico usando diversos sistemas tecnológicos de manera simultánea y natural, permitiendo una mayor autonomía en la adquisición de habilidades y saberes.

Palabras clave: Aprendizaje colaborativo; Herramientas digitales interactivas; Docencia Arquitectónica; Experiencia de usuario; Autonomía.

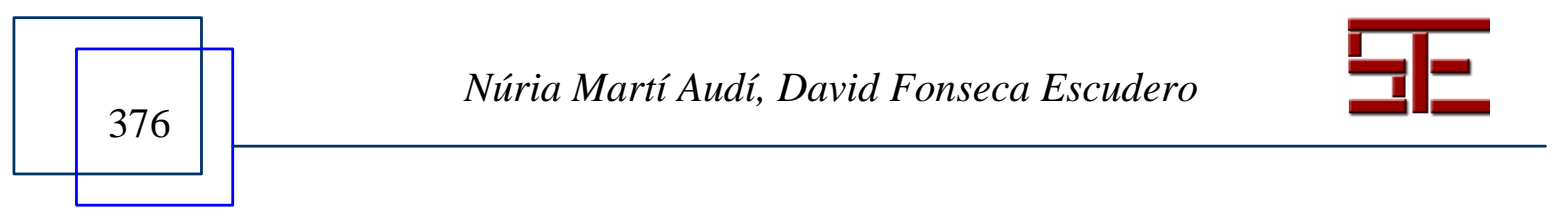




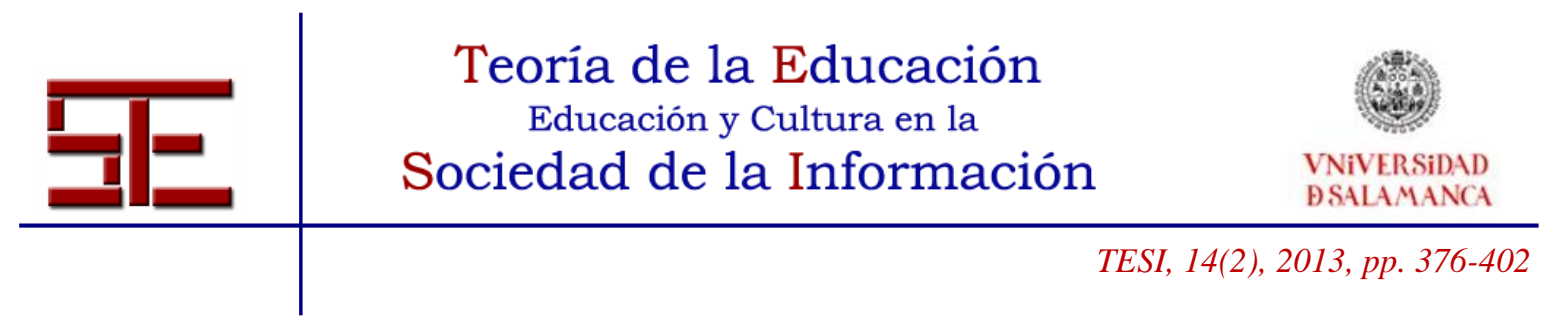

\section{ACTIVE LEARNING UNITS INTERRELATED USING TIC'S TOOLS IN ARCHITECTURAL CONSTRUCTION.}

Abstract: The presence of new technologies in the university world is a matter of fact. Nevertheless, it has not always blended correctly as in many cases TIC incorporation has not taken alumni opinion understood as final users. A correct implementation might evaluate some variables as satisfaction, need, interest and finally that versatility to adapt it to proficient professional training on a regular basis. This paper analyses a new approach to learning in the field of Architectural Construction based on a series of strategically designed and interactive units. The centre of these is the collaborative project; this is based on complex problem-solving situations akin to the professional world; where theory and practice are combined in a discovery-learning process. The tools of Information and Communication Technology are applied, simultaneously facilitating the student's autonomy in acquiring skills and knowledge.

Key words: Collaborative learning; interactive e-learning; Autonomy; Architectural teaching; User experience; Autonomy.

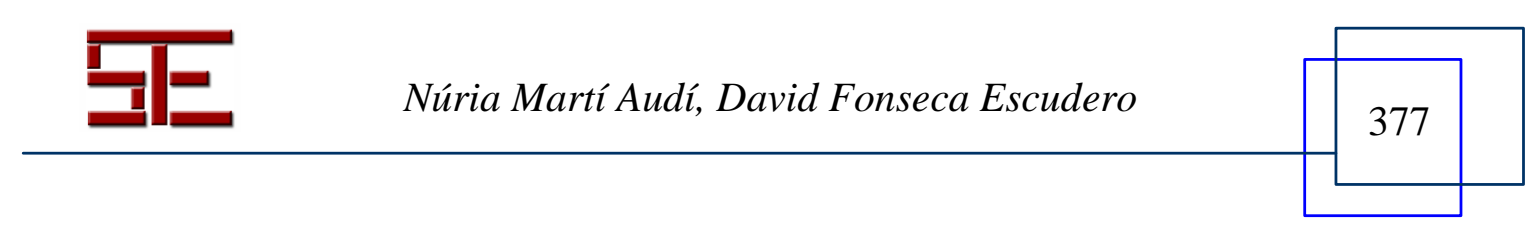




Teoría de la Educación
Educación y Cultura en la
VNIVERSIDAD
DSALAMANCA

\section{APRENDIZAJE COLABORATIVO CON IMPLEMENTACIÓN NATURAL DE HERRAMIENTAS TIC EN LA CONSTRUCCIÓN ARQUITECTÓNICA.}

Fecha de recepción: 14/01/2013; fecha de aceptación: 22/04/2013; fecha de publicación: 30/07/2013

Núria Martí Audí

nmarti@salleurl.edu

Escuela de Arquitectura La Salle, ETSALS. URL

Barcelona, España

David Fonseca Escudero

fonsi@salle.url.edu

Escuela de Arquitectura La Salle, ETSALS. URL

Barcelona, España

\section{1.- INTRODUCCIÓN.}

La implantación y uso de la tecnología para el aprendizaje en las aulas conlleva la necesidad de modernizar tanto los contenidos como la metodología docente, adaptándolos a lo que podríamos llamar los "nuevos tiempos". Estos, no son más que el reflejo de una sociedad en constante cambio, donde el alumnado se forma, convive y uso desde edades muy tempranas, todo tipo de tecnologías de red como Internet y todos sus variados aplicativos y distintos tipos de dispositivos móviles. Los llamados "nativos digitales" (Nativos Digitales, 2007) están llamados al aburrimiento y a un potencial fracaso educativo si la infraestructura del aula y la metodología de aprendizaje no se adapta a estas tecnologías familiares para ellos, en las cuales se encuentran más cómodos y activos en su proceso de aprendizaje.

En éste contexto social se implanta por el Espacio Europeo de Educación Superior (EEES), el nuevo modelo de aprendizaje activo basado en la adquisición de competencias. En éste innovador plan educativo se promueve el aprendizaje colaborativo y el autoaprendizaje del alumno, huyendo en la medida de lo posible de las clásicas "lecciones magistrales" pasivas que alejan al profesor del alumno nativo digital. En este sentido la integración de las herramientas tecnológicas juegan un papel decisivo en la metodología docente (Guiliarte, 2008).

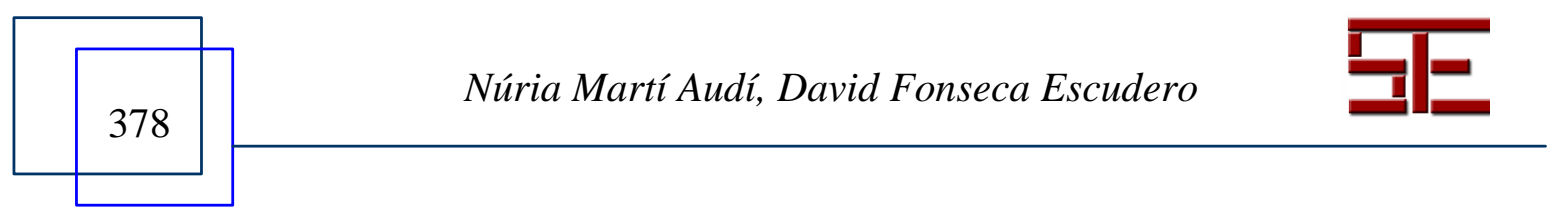




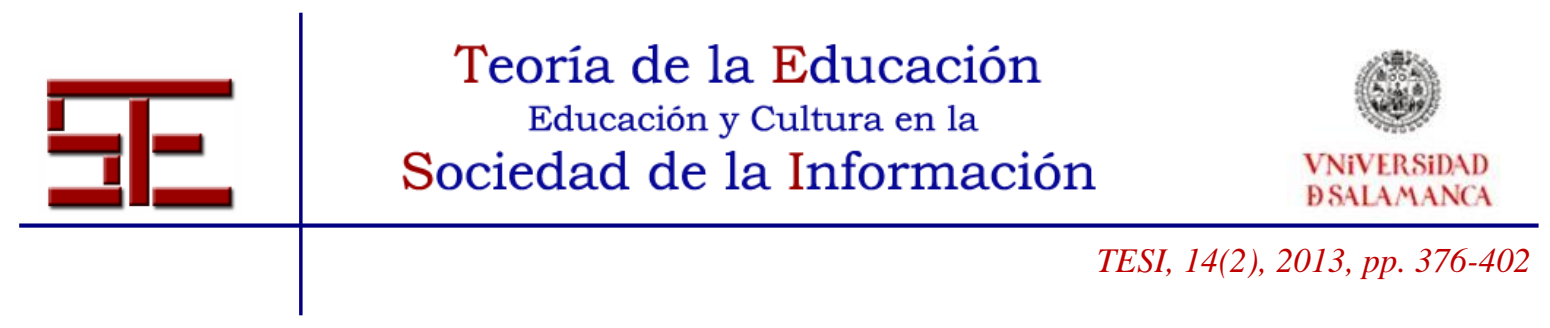

Pero, no toda implantación tecnológica y migración a contenidos digitales y plataformas de auto-aprendizaje se está realizando de manera correcta. En muchos casos la accesibilidad ilimitada a contenidos sin discretización, la falta de planificación en las tareas, así como un desconocimiento de las tecnologías implicadas y la falta de soporte posterior por parte del profesorado u equipos técnicos, son causas comunes que generan descontento en el alumnado y resultados no tan positivos a los esperados en dicha implantación.

Por dichos motivos, es de vital importancia en cualquier nueva experiencia docente que use las llamadas Tecnologías de la Información y la Comunicación (TIC), donde encontramos agrupados tanto técnicas, dispositivos como tecnologías, definir metodologías concretas de captación, análisis y evaluación de los resultados, adaptadas en cada caso al sistema o tecnología a introducir. Controlando estos parámetros, podremos analizar posteriormente en qué medida es útil o no el uso de dichos métodos en campos específicos de la educación general y en especial de la universitaria, último escalón en muchos casos antes de iniciar su etapa profesional.

El aprendizaje en Arquitectura, no es ajena a toda esta evolución, como disciplina teórica y práctica con gran carga visual y espacial, la aplicabilidad de las nuevas herramientas TIC le es de gran utilidad. Asimismo en el sector de la Construcción nos encontramos en un momento crítico por la situación socioeconómica y profesional y por tanto de inflexión en el reaprendizaje de la Arquitectura. Los factores a afrontar son:

- La crisis sociocultural que replantea el espacio arquitectónico.

- La crisis económica, que afecta directamente al sector de la Construcción.

- El avance y renovación permanente de sistemas tecnológicos que convierte en anacrónico el aprendizaje de "recetas".

- La adquisición de consciencia de la Sostenibilidad en los recursos limitados del planeta, la eficiencia energética, y el coste ambiental de los materiales, entre otros aspectos, que plantean un desafío en la concepción del Proyecto de Arquitectura.

Ante estos factores y frentes, los profesionales de Arquitectura, tenemos por delante el desafío de replantear la profesión y por consiguiente actualizar el entendimiento de la Arquitectura.

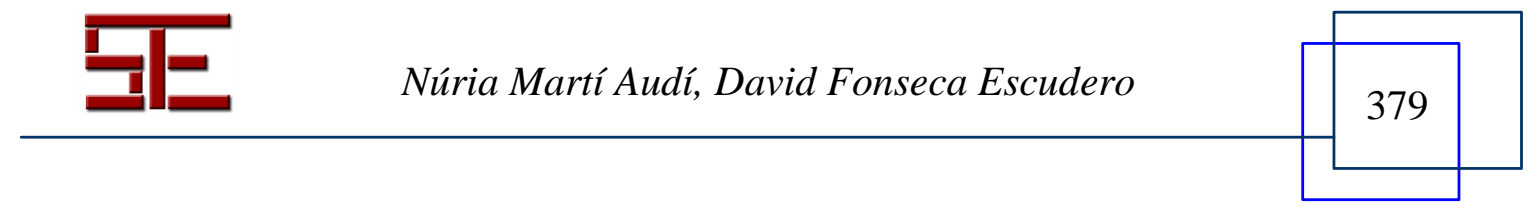




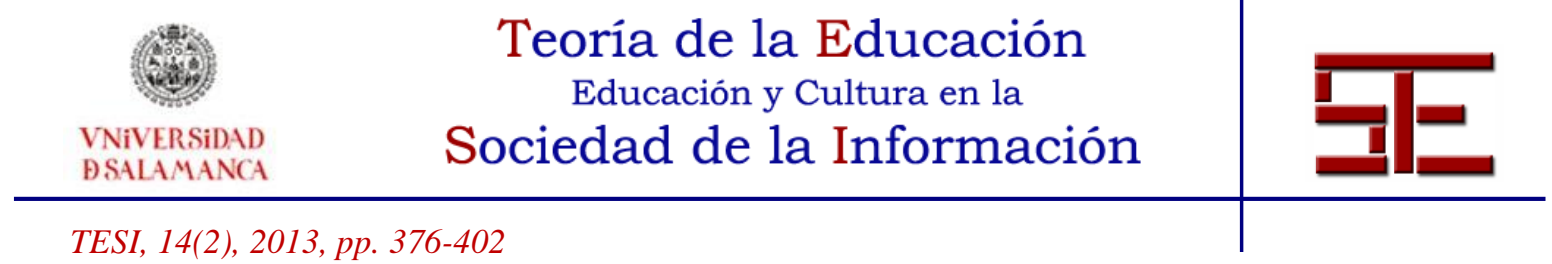

En el campo de la docencia creemos que el reto acontece por trazar una enseñanza constructiva que faculte abordar cualquier proyecto en cualquier situación, con sentido crítico reflexivo, metódico, analítico y operativo, y con proyección futura. Con este contexto nos planteamos una nueva aproximación a la educación en Arquitectura que incorpore: aprendizajes cruzados, basados en problemas (del inglés Problem-based learning -PBL), tratados de manera colaborativa (Font, 2004); y aprendizajes de proyectos estratégicamente organizados para adquirir las máximas competencias posibles de tal forma que se pueda acreditar al alumno en su propio aprendizaje autónomo (Pozo y Monereo, 1999).

En esta tipología de proyectos educativos, las herramientas TIC siempre supervisadas activamente por la comunidad de aprendizaje, son fundamentales para dinamizar el papel participativo del alumno y elaborar de forma conjunta su propio conocimiento (Álvarez, Ayuste, Gros, Guerra y Romañá, 2005).

\section{2.- MARCO TEÓRICO.}

En el presente artículo se muestra el diseño de la asignatura de Construcción Arquitectónica de segundo curso del grado de Arquitectura mediante distintas unidades de aprendizaje con implementación de las TIC.

El artículo dirige la atención al nuevo paradigma de formación del EEES con la implementación de las TIC de manera natural, como mecanismos de trabajo intrínsecos a la formación académica y al futuro profesional, haciendo hincapié en:

- Aprendizaje de saberes y habilidades del alumno mediante herramientas y técnicas colaborativas que permitan generar conocimiento de manera autónoma al alumno.

- Migración de contenidos clásicos a nuevos materiales digitales y habitualmente interactivos,

La dificultad de implantación de manera adecuada y natural de las TIC en el proceso educativo y la falta sistemática de datos que valoren de manera concreta y correcta la adecuación de estos nuevos contenidos eminentemente visuales en el proceso de aprendizaje del alumno, son retos visibles y evidentes, como se señala en "Innovación docente: Docencia y TICS" (Guiliarte, 2008), a los cuales el diseño estratégicamente planificado de la asignatura de Construcción intenta dar respuesta.

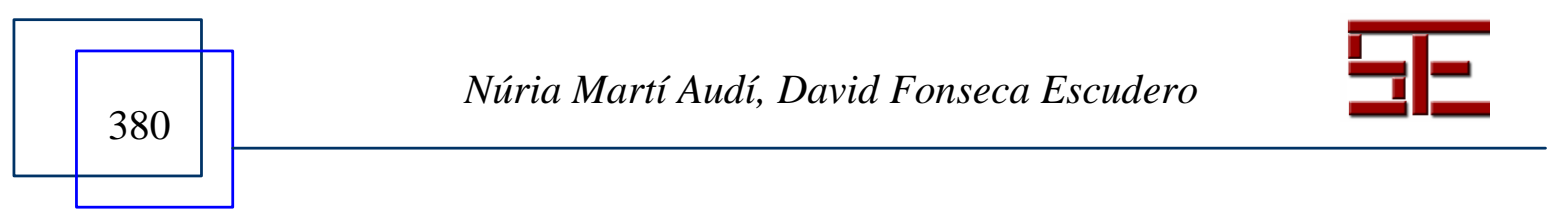




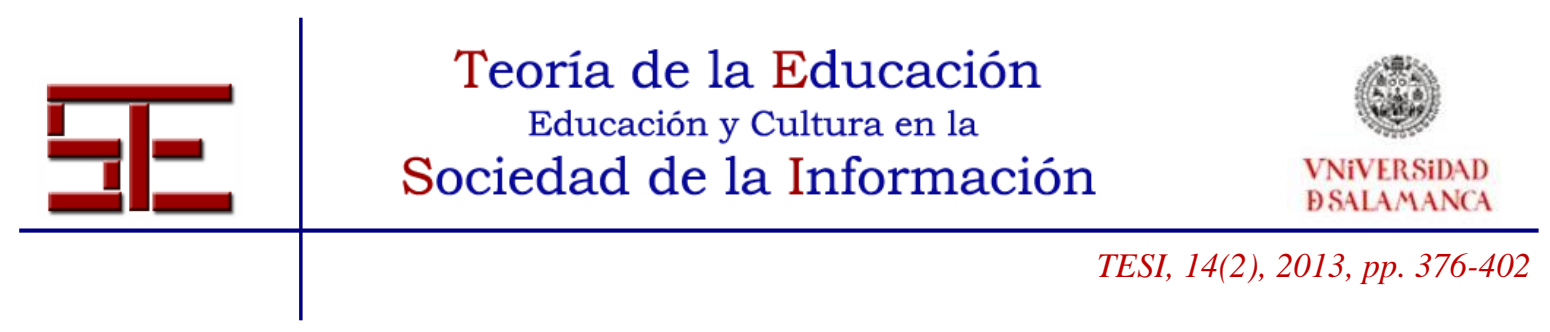

\section{1.- Retos y problemas en la introducción tecnológica en docencia.}

Antes de proponer un cambio metodológico en cualquier área, por el simple motivo de una modernización mal entendida, habría que evaluar el sector y diseñar conjuntamente las técnicas de aprendizaje con las tecnológicas. En el caso del sector educativo AEC (Architecture, Engineering and Construction) el uso de TIC, de recursos interactivos y de herramientas con un alto contenido visual o espacial el éxito está constatado, siendo un claro ejemplo el del MIT (Massachusetts Institute of Technology), quienes muestran y ejemplifican sus contenidos en "iTunes U" de Apple (Knox, 2007). Ahora bien, las universidades principalmente españolas y europeas, utilizan dicho entorno tan solo como un dispositivo publicitario y de presentación, sin explotar las capacidades didácticas que posee.

$\mathrm{Al}$ respecto, es fácil encontrar una reticencia general al uso de tecnologías que suelen estar asociadas al ocio o las relaciones personales, como los distintos dispositivos móviles (teléfonos, tabletas, ipods,...), Internet, o simplemente mensajes de texto o de audio como los podcasts. En este aspecto tanto docentes como estudiantes, deben ser conscientes de las posibilidades que estos dispositivos y de los contenidos generados de manera adecuada pueden aportar pero a la vez ser conscientes de la desubicación de la formación y de la pérdida de valor añadido a la misma y la percepción global. Al respecto podemos encontrar estudios que vinculan el uso de estas tecnologías a un mayor rendimiento académico (Callaway, 2009), uno de los principales miedos del profesorado más reticente a esta implementación.

Otra de las grandes trabas a la hora de implantar las TIC en docencia la encontramos en el entorno administrativo: los profesores deben estar formados (Georgina y Olson, 2007) y ser capaces de dar soporte en todo momento al alumno, lo cual implica por un lado la formación previa del docente y por otro lado la obtención del tiempo necesario para la generación, modificación y actualización de los contenidos, así como una evaluación posterior de todo el proceso (Champeny, Borgman, Leazer, Gilliland-Swetland, Millwood, D’Avolio, Finley, Smart, Mauotone, Mayer y Johnson, 2004). Todas estas premisas suponen una inversión económica que no todas las instituciones, y menos en este momento de crisis, están dispuestas a desembolsar (Hu, 2006) y que muchos profesores no van a realizar de manera altruista (Milliken y Philip-Barnes, 2009). Sin un docente y un entorno motivados, el éxito de la implantación será improbable y la percepción del uso de las TIC no será satisfactoria para el estudiante, degenerando en un desinterés como mínimo en la materia, justo el efecto contrario al buscado.

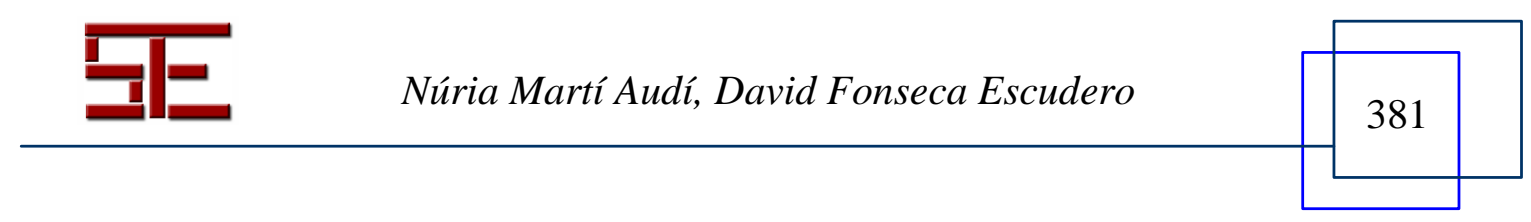




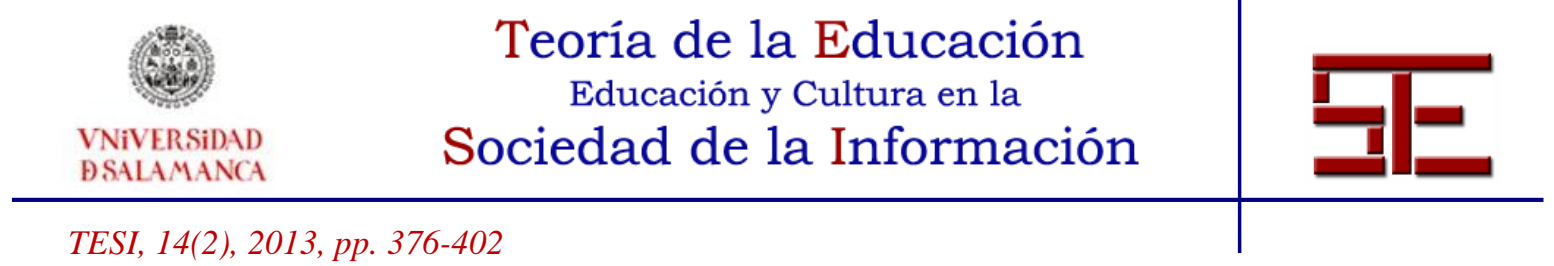

En definitiva, creemos que para obtener una óptima respuesta en una implantación TIC, debe haber: una predisposición clara por parte del profesorado y la institución, una consulta previa al alumnado para identificar carencias, sugerencias y motivación de cara al uso y cambio de hábitos en sus rutinas de estudio al incorporar determinadas TIC, y por último un seguimiento posterior y evaluación del grado de satisfacción, adaptación y aprovechamiento conseguido con dichos métodos.

\section{2.- Riesgos y buenas prácticas en docencia usando TICs.}

Llegados a este punto, queda claro que la tecnología es una pieza clave en la sociedad actual a todos los niveles, pero que no puede ser la piedra filosofal a los problemas educativos, ya que su simple presencia en el aula no asegura una mayor eficiencia académica del alumno (Rodriguez-Izquierdo, 2010). Es en esa ansiada búsqueda de un uso eficiente de la tecnología (Rogers, 2000), (Bates y Pole, 2003), donde encontramos definidas en trabajos previos las llamadas "Buenas Prácticas Educativas con TIC", acciones complejas y heterogéneas que en muchos casos no son reutilizables de un ámbito a otro (Valverde, Garrido y Fernández, 2010). Habitualmente, en dichos trabajos se buscan los mejores métodos para el uso de recursos en Internet (Área, San-Nicolás y Fariña, 2010).

El problema surge cuando se centra el uso de Internet como principal herramienta tecnológica y/o de soporte en la docencia. Un recurso habitual en los últimos años ha pasado por sustituir libros y apuntes impresos (los cuales habitualmente tenían unos mínimos de calidad pre-establecidos), por recortes, montajes y enlaces en cualquier formato, idioma y muchas veces sin un filtro previo. Aunque el fin y la justificación del docente para este procedimiento es dar la mayor información posible al alumno para que disponga de todos los datos, la falta de filtraje, maquetación y control de los contenidos por parte del profesor ha degenerado en un exceso informativo, un más difícil seguimiento de la materia por parte del alumno y por consiguiente una menor eficiencia en los resultados. Cualquier práctica docente que use las TIC debe ser capaz de:

- Aportar una mejor comprensión en la representación y formulación de los conceptos de la materia.

- Mejorar las dificultades del proceso de aprendizaje sin olvidar el conocimiento previo de los alumnos.

- Ser un instrumento natural que permita un entorno flexible y colaborativo lo más alejado de un simple repositorio de información.

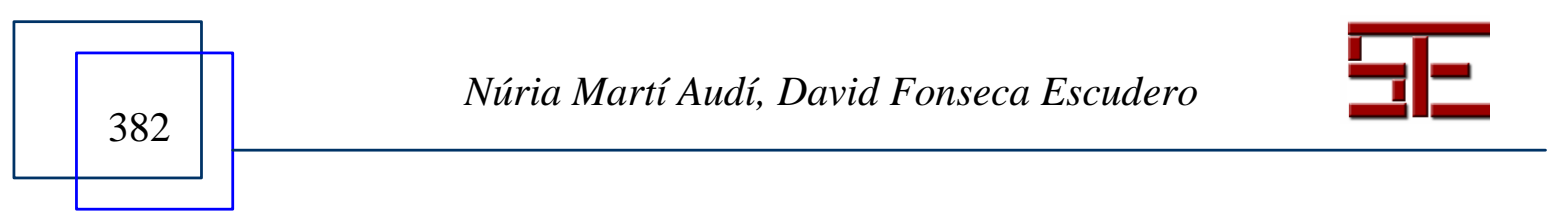




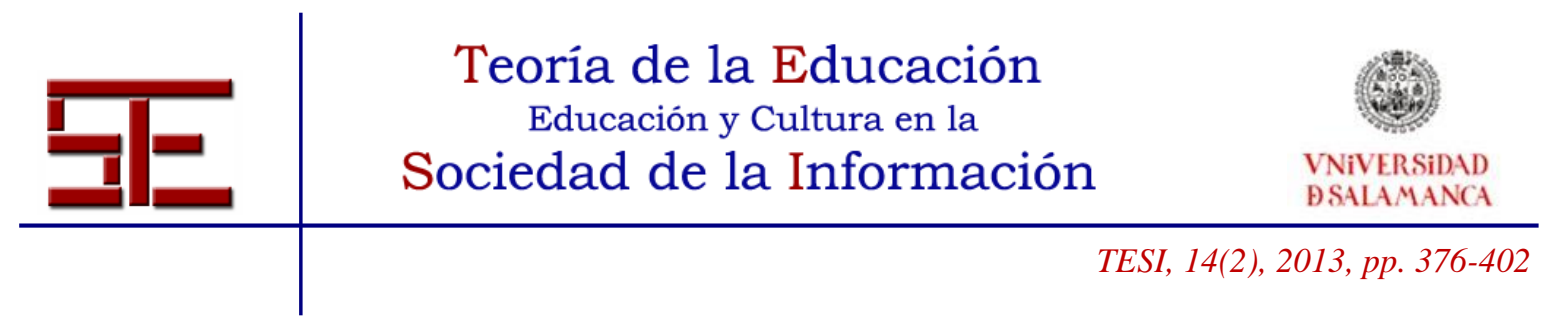

Si se consiguen estos principios, no solo mejoraremos previsiblemente las habilidades de auto-aprendizaje y gestión de recursos del alumno, sino que de manera intrínseca se le estará dotando de capacidades ligadas a la investigación y la reflexión (Prieto, Rodriguez, Hernández y Queiruga, 2011), capacitando al estudiante en la profundización y comprensión de los conocimientos presentados.

\section{3.- Prácticas colaborativas aplicadas en el ámbito arquitectónico y en la generación de contenidos digitales.}

Sin duda, es casi imposible reseñar la multitud de trabajos en todos los ámbitos docentes y científicos que han disertado y experimentado acerca del "Diseño Educacional Colaborativo" (Kondratova y Goldfarb, 2004), (Kocaturk, 2010), (Glick, Clevenger y Porter, 2011). En nuestro caso, y dado el enfoque del diseño que nos ocupa, centrado en la enseñanza de las materias relacionadas con la Construcción Arquitectónica, creemos que un adecuado punto de partida es referenciar aquellos que han aportado nuevos enfoques AEC, especialmente en la adquisición y mejora de las habilidades espaciales del alumno.

Tal y como ya hemos enunciado, en la enseñanza arquitectónica en especial, la componente visual y espacial es uno de los aspectos más importantes con que el alumno trabaja habitualmente, estudia y debe comprender correctamente. En arquitectura, la información espacial es representada utilizando desde los métodos más tradicionales como el plano impreso y la maqueta (trabajo del 2D al 3D), llegando a métodos más actuales como los planos digitales y los modelos tridimensionales, los cuales permiten llegar a un mayor nivel de detalle, así como obtener capacidades de navegación y actualización de los posibles cambios de manera casi inmediata (Fonseca, Redondo, Sánchez, Villagrasa y Martí, 2012). Estos métodos AEC avanzados de visualización permiten tanto a los profesionales del sector como a los estudiantes trabajar no solo de manera colaborativa sino comunicar sus ideas y en general el espacio y el proyecto de una forma mucho más eficiente (Bouchlaghem, Shang, Whyte y Ganah, 2005).

Una de las hipótesis más establecidas parte de la idea que los estudiantes capaces de dominar los métodos AEC, que determinadas herramientas TIC nos ofrecen, no solo van a ser capaces de llevar un ritmo de aprendizaje mucho mayor, llegar a conclusiones proyectuales más rápidas y mejorar las habilidades definidas en los diversos planes de estudio (Leopold, Górska y Sorby, 2001), sino que su aprovechamiento académico se va a ver reflejado en sus actividades profesionales futuras. El uso de determinadas TIC colaborativas permitirá el diseño y generación de proyectos más funcionales, sostenibles e inteligentes, lo que en algunos sectores se ha llamado el Intelligent Design-Based

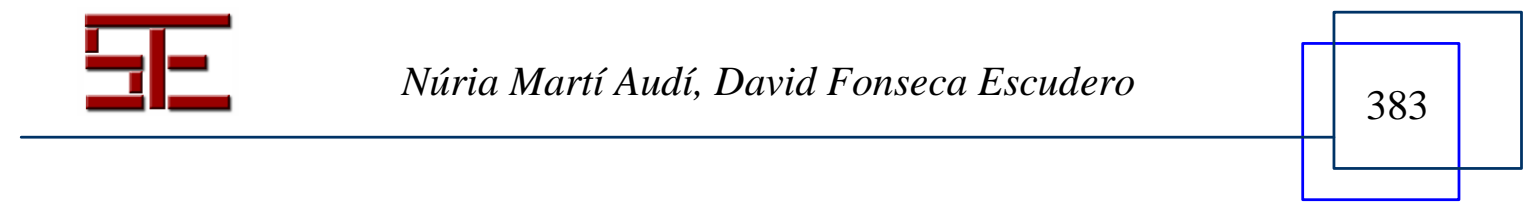




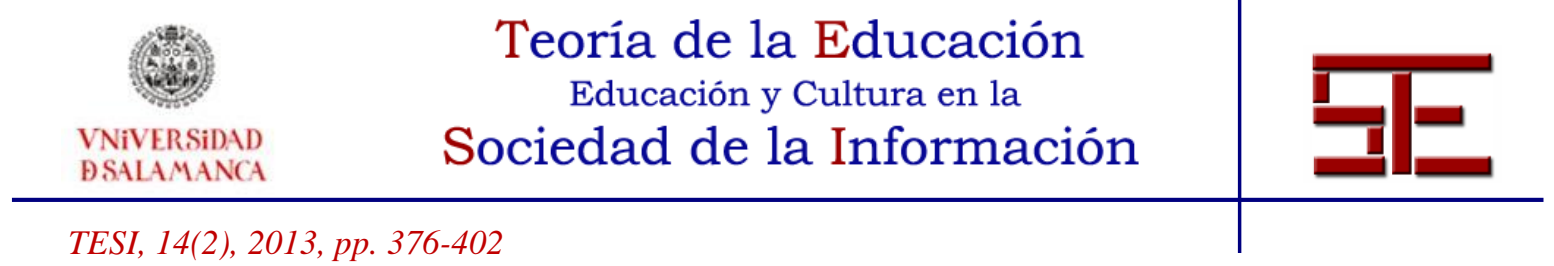

Learning - IDBL (Nawari, 2010), y que actualmente en España su punta de lanza representativa son aquellos programas con tecnología BIM (Building Information Modeling).

Otra herramienta a tener presente es la documentación on-line que permite agrupar en un mismo documento distintas tecnologías informáticas y por lo tanto interrelacionar fácilmente conceptos teóricos y prácticos facilitando el aprendizaje. Por una lado hay que destacar su actual facilidad y recursos de generación, con infinidad de procesadores de texto y programas de maquetación de contenidos (Jabi, 2003), (Martens y Turk, 2003). Pero por otro lado, hay que tener en cuenta la necesidad constante de actualización y el tiempo necesario para su maquetación (la cual puede llegar a ser muy compleja como en el caso de los libros interactivos que propone la plataforma iBook de Apple). Es necesario evitar plasmar directamente los libros impresos al formato digital para aportar muchos más servicios a este tipo de contenidos: capacidades multimedia, interactividad, trabajo colaborativo y "auto-generativo" y que en definitiva, involucre al alumno no solo como un simple consumidor de información, sino como un potencial generador y administrador de los mismos, lo que actualmente y de manera genérica se conoce como Web 3.0 ó "usuario 3.0". Buscando este enfoque, la Wikipedia se sitúa como uno de los primeros ejemplos a citar, y que algunas universidades utilizan de manera activa justamente para conseguir la generación colaborativa de los contenidos entre profesores y alumnos (Mareca y Bosch, 2011). No obstante, el gran problema de este soporte vuelve a ser la falta de control en el proceso de publicación y la compartición de la información, una idea poco extendida en el marco universitario español.

Por dichos motivos, un entorno que se está imponiendo por sus capacidades de autogestión, que permite un control del flujo docente adecuado, y su limitación de acceso según el criterio del profesorado, es el trabajo con plataformas tipo Moodle: un sistema de gestión de cursos, o CMS (del inglés Course Management Systems), de código abierto, que permite una interrelación entre el profesorado y el alumnado de cualquier materia, y que genera en un entorno controlado de contenidos capaz de ajustarse a las necesidades particulares de cada materia y área docente (Berggren, Burgos, Fontana, Hinkelman, Hung, Hursh y Tielemans, 2005), (Machado, 2007). Al respecto, hay diversos trabajos previos que analizan los diversos CMS existentes y sus características (Unal y Unal, 2011), siendo el Moodle uno de los preferidos por los alumnos dada su usabilidad, pero en nuestro caso la imposición de trabajo dicha plataforma viene condicionada al ser el sistema de Intranet de toda la Facultad de La Salle, al cual llamamos eStudy.

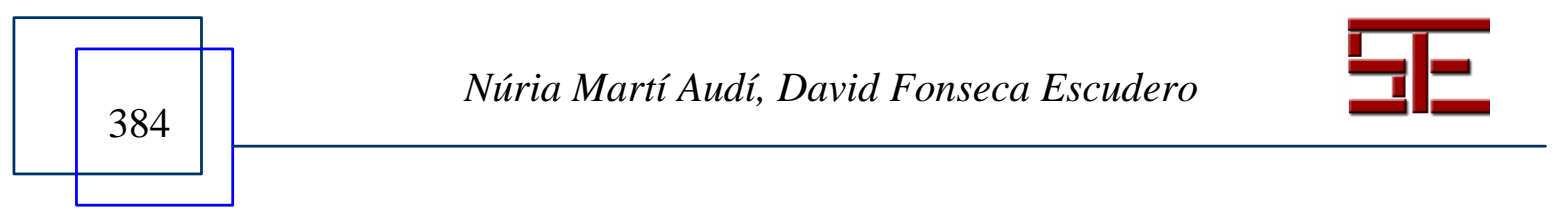




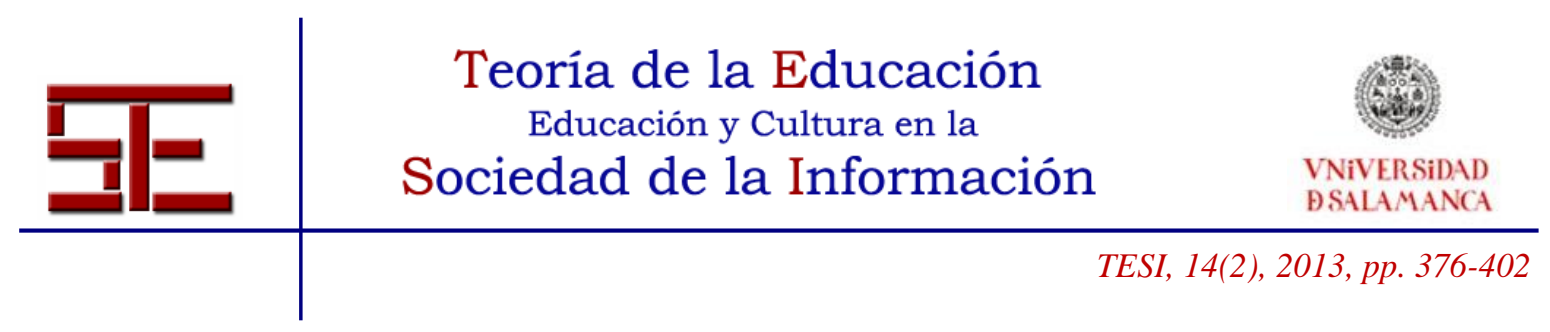

\section{3.- MARCO DOCENTE. ASIGNATURA CONSTRUCCIÓN II.}

Las asignaturas del Área de Construcción Arquitectónica son troncales en los cinco años del grado de Arquitectura plasmándose como imprescindible en la máxima del Proyecto Fin de Carrera donde se considera que: "el alumno tiene que ser capaz de construir lo que ha proyectado".

Con esta premisa, la enseñanza de Construcción en el primer y segundo ciclo del grado es distinta. En los dos primeros curos del primer ciclo existe una asignatura específica de Construcción de gran carga lectiva (6 y 9 créditos ECTS, respectivamente) y a partir del segundo ciclo la enseñanza de ésta se integra dentro de la asignatura de Taller, la cual aglutina también las otras disciplinas técnicas del Proyecto Arquitectónico, de manera práctica, equilibrada y armónica.

A partir de esta estructura académica del área de Construcción, las asignaturas de primero y segundo tienen que agrupar los conocimientos primordiales y globales de la disciplina. Por lo tanto, el objetivo que se proyecta es proporcionar al alumno, en estos dos cursos, una visión conjunta de todo el conocimiento teórico, en cuanto a saberes y ser competente en su aplicabilidad. A su vez, debe ser capaz metodológicamente mediante competencias transversales en el ámbito de las habilidades, de especializarse de manera autónoma en los distintos temas de manera analítica y reflexiva (Alvarez, Ayuste, Gros, Guerra y Romaña, 2005).

A continuación se describe en profundidad el diseño y la metodología de la asignatura de Construcción II donde se propone un modelo de aprendizaje activo basado en distintas unidades estratégicamente interrelacionadas, en las que la plataforma eStudy y las herramientas TIC tienen un papel colaborativo fundamental.

Estas unidades de aprendizaje están formadas por:

1. Taller de proyecto práctico colaborativo, PBL Taller 0.

2. Seminarios de teoría vinculados a actividades de investigación.

3. Jornadas de "tecnología in situ".

4. Materiales docentes: apuntes digitales mediante plataforma moodle _estudy_, tutorías y el laboratorio de consultas.

\section{4.- UNIDADES DE APRENDIZAJE.}

Las unidades de aprendizaje están planteadas estratégicamente con distintas Técnicas de Aprendizaje y Conocimiento (TAC), estructurándose todas ellas se en tres estadios bien definidos e implementándose en todas ellas las TIC de forma natural.

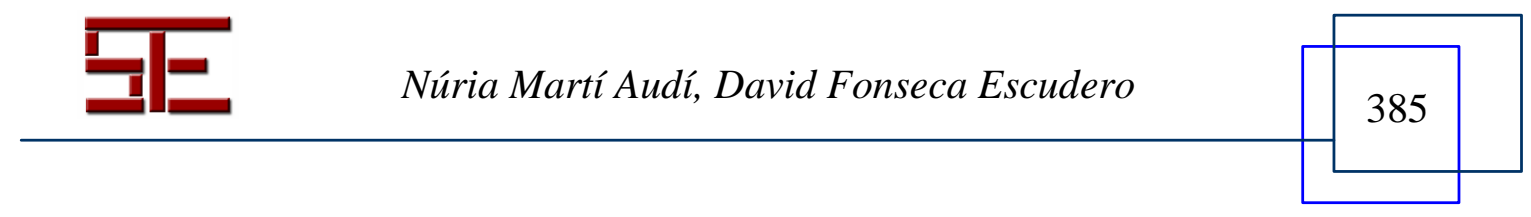




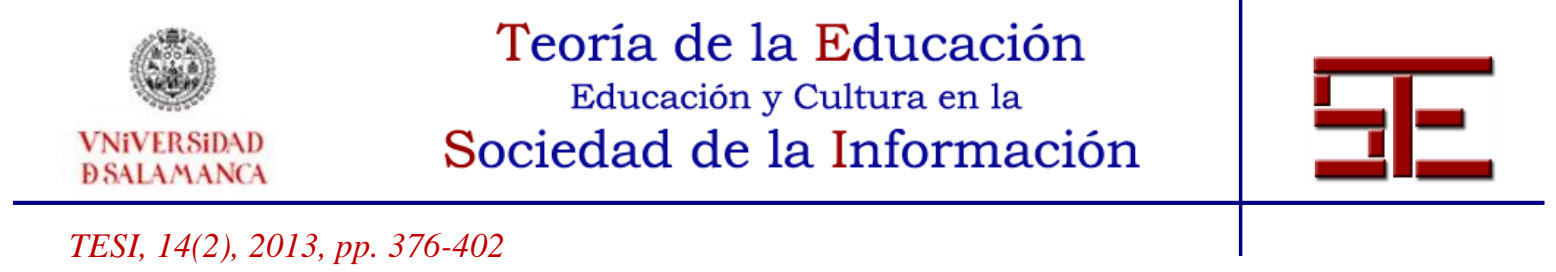

\section{1.- Proyecto práctico colaborativo. Taller 0 .}

El proyecto práctico o Taller 0 se considera dentro del esquema académico del grado de arquitectura como el antecedente del Taller del segundo ciclo, siguiendo su mismo discernimiento y estructura pero con la diferencia de la interrelación y apoyo de las otras unidades de aprendizaje y con un punto de partida totalmente definido al tratarse de un edificio construido.

La estrategia de formación se basa en la resolución de un problema real complejo donde se tiene que resolver el proyecto ejecutivo (llegando a escala de detalle 1:10) de un edificio construido de un arquitecto reconocido de mediados de siglo $\mathrm{XX}$, con la dificultad de tener que aplicar las normativas técnicas actuales y reinterpretando la solución existente, manteniendo la estética y composición del edificio construido. Con este planteamiento el problema planteado no tiene una única solución y por lo tanto los alumnos tienen que ser capaces de pensar, aplicar, investigar y transformar el conocimiento con el fin de resolver el proyecto.

El taller se realiza en equipo de dos o tres alumnos para crear debates, abarcar y manejar la máxima información posible, siendo la colaboración el eje central del trabajo académico.

La estructura en tres estadios de los seminarios se basa en:

a. Enunciado del problema complejo. PBL.

b. Investigación y adecuación de las soluciones.

c. Exposición y debate.

\section{1.a.-Enunciado del problema complejo}

Al tratarse de un problema amplio, este se divide en partes y se le presenta al alumno el primer día de clase el mapa conceptual para poderlo comprender globalmente. Estas partes o unidades del problema coinciden con las temáticas de los seminarios teóricos y son planteadas en el orden y con la metodología a semejanza de un proyecto arquitectónico real.

En esta fase el alumno tiene que enunciar y plantear las demandas del problema, siendo consciente que de su formulación depende una solución u otra. La ayuda que dispone en este momento el alumno es la documentación almacenada en el eStudy; ya que en este punto el alumno aún no ha recibido la exposición de los seminarios teóricos, los cuales se imparten en la semana siguiente (Fig.1).

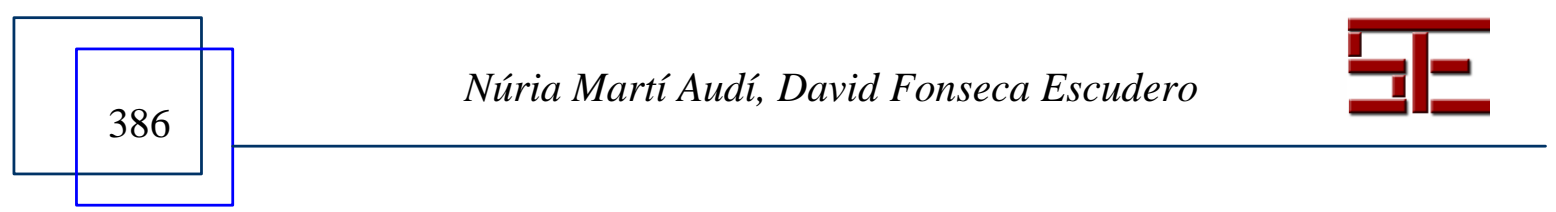




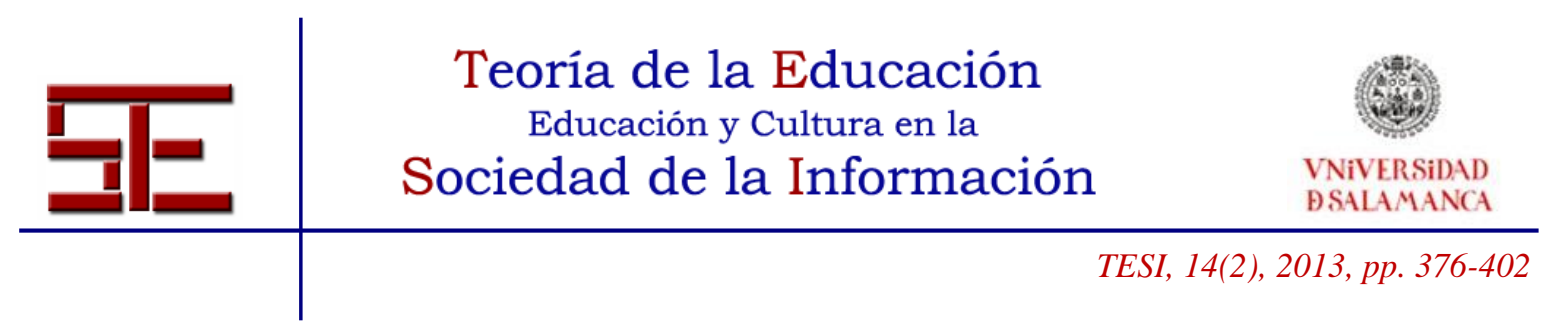

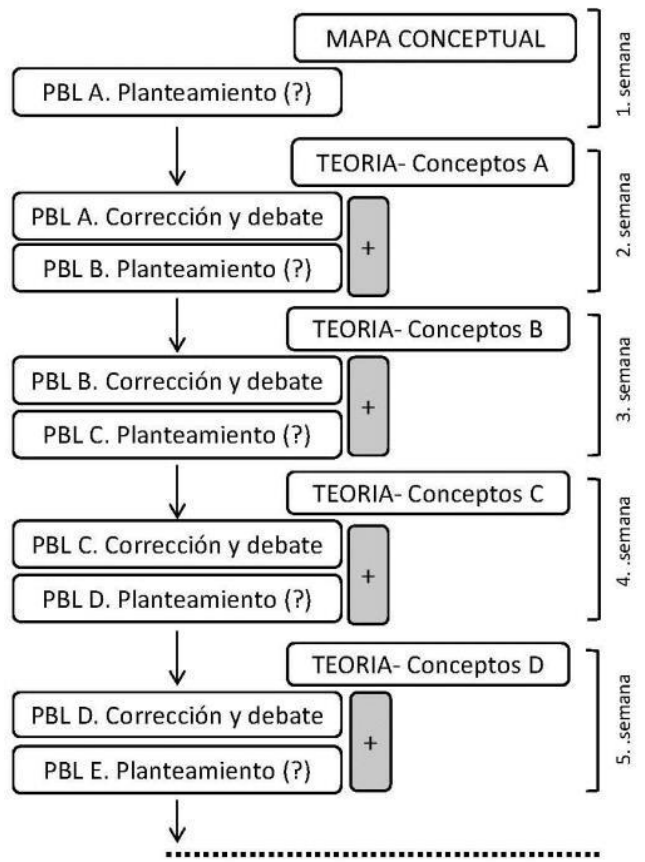

Figura 1. Interrelación Taller 0 y seminarios teóricos.

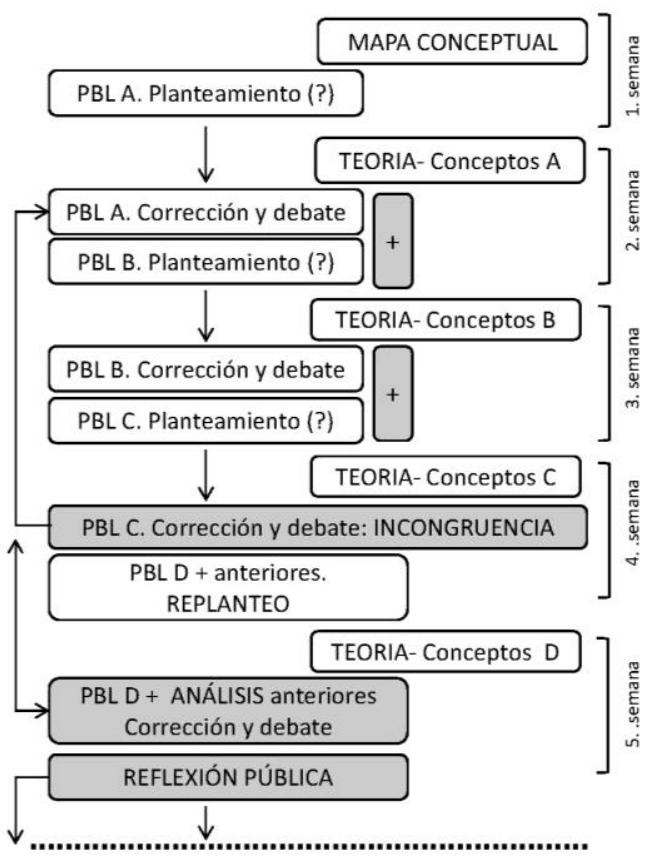

Figura 2. Replanteo PBL.

\section{1.b.-Investigación y adecuación de las soluciones}

Una vez planteado el problema y establecidas las demandas, en esta fase el alumno tiene que resolverlo a través de investigación de documentación, de prueba y error de la solución planteada mediante distintas comprobaciones a través de herramientas TIC, de debates entre equipos y finalmente de correcciones con el profesor tanto a través de fórums en el eStudy como presencialmente en clase.

Como la solución es abierta, el profesor no tiene en su mano el resultado final y avanza e investiga con los alumnos para obtener la solución más adecuada (Collazos, Guerrero y Vergara, 2001), mostrándoles distintas maneras de discernir e investigar. En este caso el profesorado es un mediador cognitivo ya que no se le da al estudiante una única solución ni una única manera de pensar. En este PBL colaborativo los equipos de tres alumnos tienen que organizarse el trabajo, siendo ellos mismos los responsables de repartir roles y de responder por igual frente al profesor. Los estudiantes se hacen cargo de su propio aprendizaje y se auto regulan, además de entender que el aprendizaje es social y receptivo a ideas de otros; de tener una mente abierta para conciliar con propuestas y argumentos contradictorias u opuestos (Bartley, 2007).

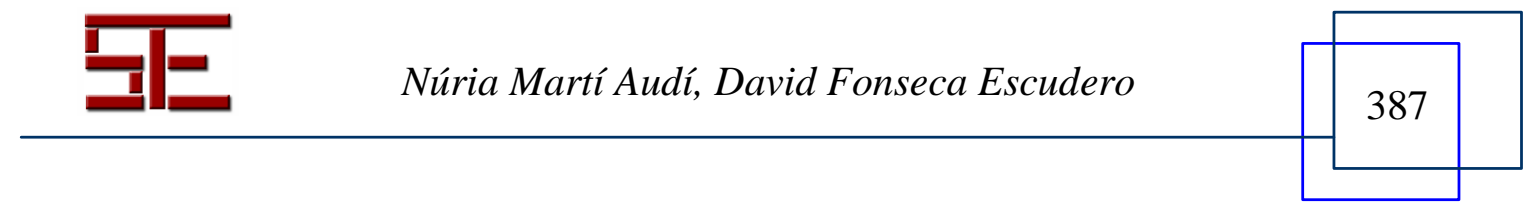




\begin{tabular}{cc}
\multicolumn{1}{c}{$\begin{array}{c}\text { Teoría de la Educación } \\
\text { Educación y Cultura en la } \\
\begin{array}{c}\text { VNiVERSIDAD } \\
\text { BSALAMANCA }\end{array}\end{array}$} \\
\hline TESI, 14(2), 2013, pp. 376-402 & Sociedad de la Información \\
\hline
\end{tabular}

\section{1.c.-Exposición}

En esta fase cada equipo realiza una exposición de su propio trabajo y justifica las soluciones abordadas. El profesor aborda los errores que se han cometido y con todo el grupo se intenta encontrar la solución (Fig.2). Muchos errores provienen no de la solución al problema si no de la contradicción entre las distintas soluciones que conforman el problema complejo global. Aunque dividido el problema, queda claro que todas las soluciones forman parte de una solución conjunta y que por tanto todas están vinculadas entre sí y tienen que adecuarse la una a la otra. Por lo tanto si se llega a una contradicción, se tiene que volver a replantear simultáneamente las respuestas opuestas para dar con una acorde con el conjunto.
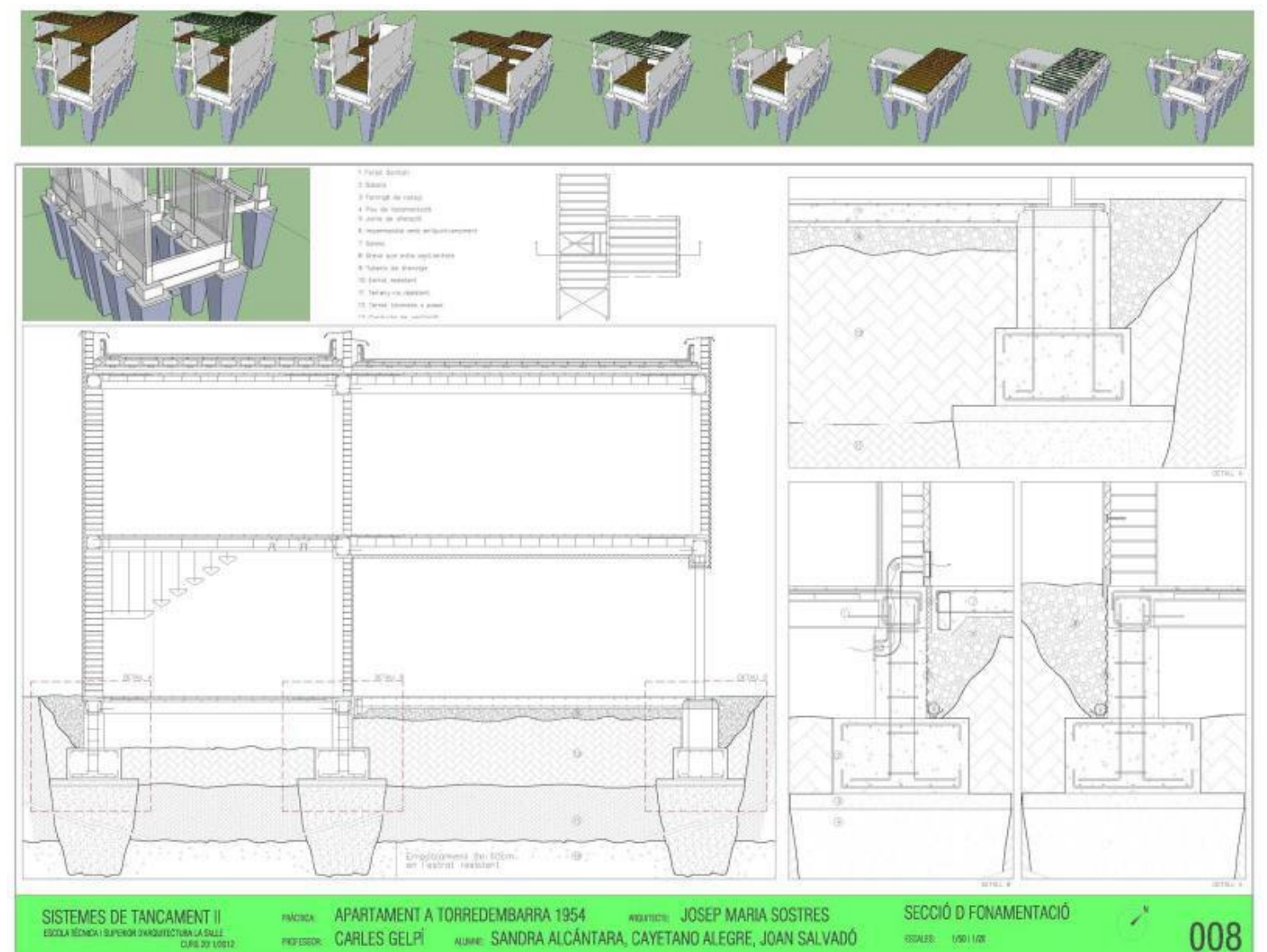

Figura 3. Ejemplo de presentación: formato que incluye distintos tipos de representación 2 y 3D con distintas escalas gráficas.

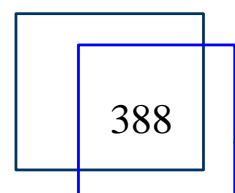

Núria Martí Audí, David Fonseca Escudero

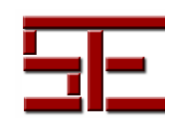




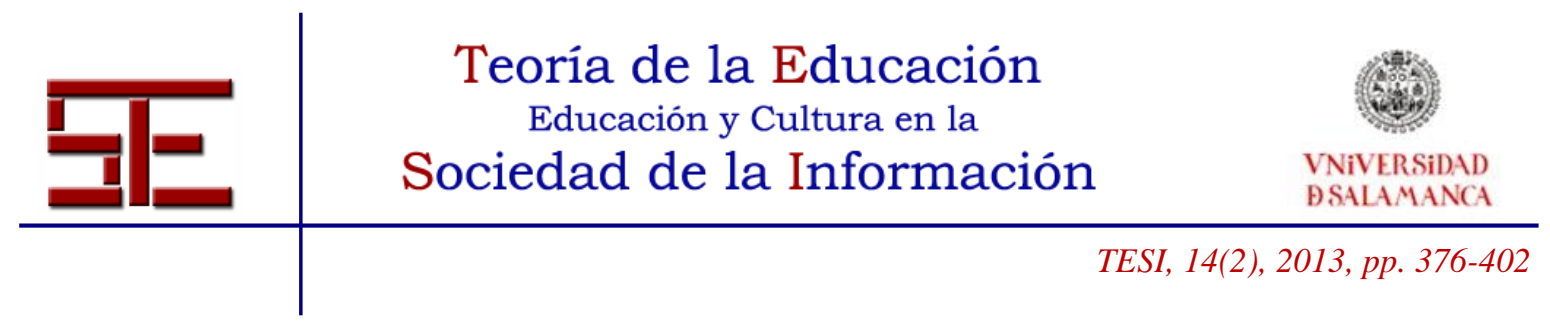

La entrega final se realiza en horario lectivo (Fig.3) y se aprovecha para realizar una evaluación oral con preguntas teóricas a la par que se justifican las soluciones adoptadas a la práctica del Taller desde una mirada global. De esta manera se cierra la interrelación entre las distintas unidades de aprendizaje.

\section{2.- Seminarios participativos y tareas asociadas de auto corrección y auto evaluación.}

La estrategia de formación se basa en seminarios activos donde el alumno participa en la elaboración de su propio conocimiento y profundiza en partes de éste a base de tareas paralelas con distintas técnicas de aprendizaje (Fig. 2).

La estructura de los seminarios se basa en:

a. Clases teóricas participativas.

b. Píldoras: exposición de imágenes (de procesos de ejecución de obra).

c. Tareas prácticas.

\section{2.a.- Clases teóricas participativas}

Las sesiones de clase teórica se realizan a través de presentaciones orales que siguen siempre el mismo formato y guión; tratándose primero los conceptos, luego las demandas del sistema y finalmente las estrategias constructivas o de usabilidad. Por lo tanto se trabaja en abstracto de lo general a lo particular y siempre tratando temáticas cerradas en cada sesión.

El hecho de mantener siempre la misma estructura permite al alumno relacionar y extrapolar conceptos entre las distintas temáticas (Coll, Palacios y Marchesi, 1993).

Estas sesiones son participativas ya que el alumno ha consultado los apuntes con anterioridad en la plataforma del estudy de la asignatura, por necesidad del taller colaborativo y por tanto se han planteado con anterioridad las dudas y las cuestiones. Consecuentemente las exposiciones pasan a ser interactivas ya que el profesor a la vez que desgrana los contenidos, los alumnos intervienen de manera dinámica.

\section{2.b.- Píldoras}

Las sesiones de "píldora de imágenes" introducen el concepto abstracto en una situación concreta para que el alumno lo contextualice para terminar de comprenderlo mejor. Las imágenes provienen de obras dirigidas por el profesorado, son fotografías o videos de procesos de ejecución de sistemas constructivos, creando una mayor empatía entre el alumno y el profesor. En este sentido no solamente se explica la parte metódica del

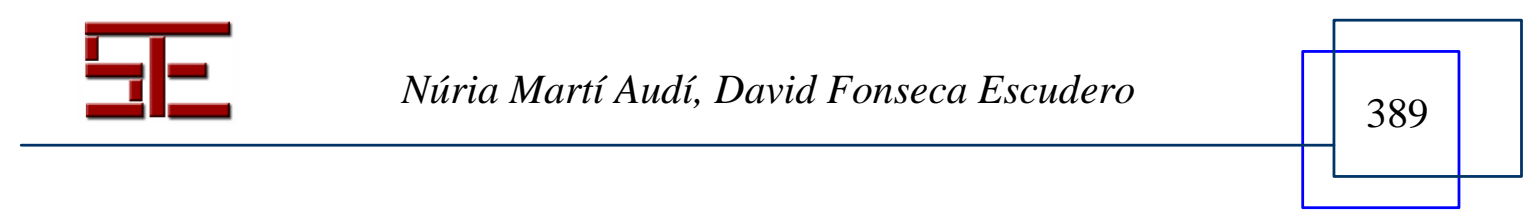




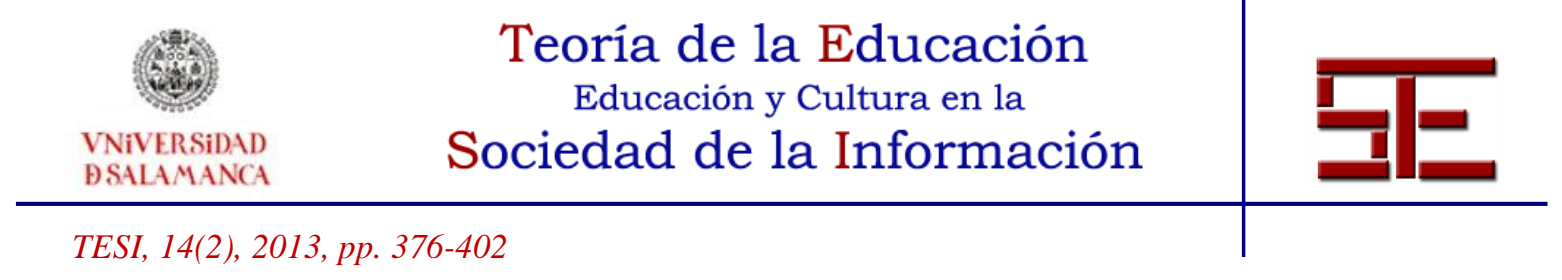

proceso y los materiales que intervienen sino que la sesión introduce vicisitudes del mundo profesional acercando al alumno a la aplicabilidad de la materia pedagógica al futuro profesional.

\section{2.c.- Tareas prácticas}

En la tercera etapa se realizan tareas individuales asociadas a las sesiones teóricas con un triple objetivo: saber y conocimiento, autonomía de aprendizaje y autoanálisis, crítica y reflexión.

El primer objetivo de la tarea se consigue impulsando al alumno a manejar y asimilar los conocimientos impartidos y a profundizar en ellos. El aprendizaje sigue un ritmo continuo evitando el aburrimiento del alumnado y manteniendo una actitud de tensión positiva.

El segundo objetivo se plantea en la instrucción de distintas TAC estratégicamente planificadas, como pueden ser: la investigación de un tema y su idoneidad técnica, el relacionar un texto con un detalle constructivo de carácter gráfico (Fig.4), pasar un detalle de $2 \mathrm{D}$ a 3D, organizar conceptos según estructura de las sesiones teóricas, definir un sistema constructivo concreto de un edificio conocido lo que implica su análisis, o la aplicación de un concepto al taller 0 para relacionar unidades de aprendizaje, entre otras ideas. 


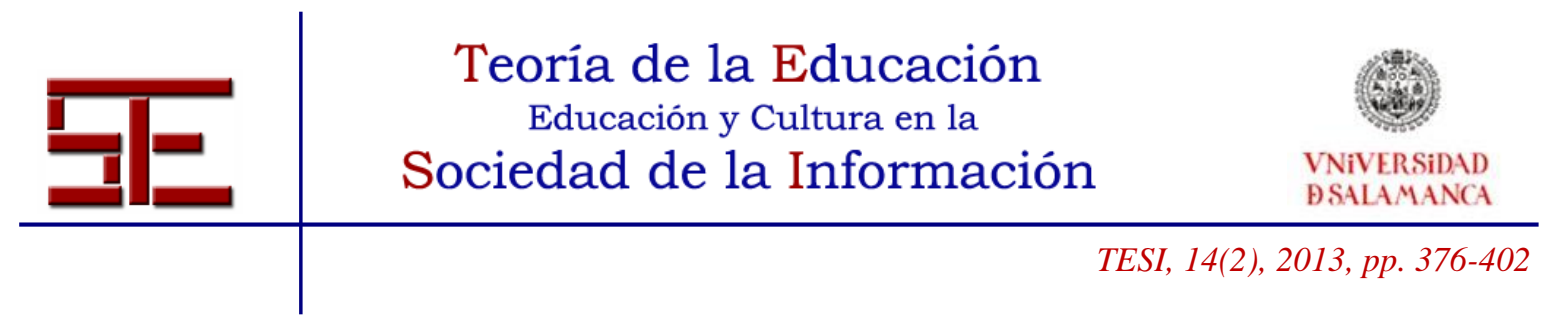

También en todas la tareas se estimula a los alumnos a trabajar distintas TIC: a través de programas informáticos de dibujo, fotografía, ofimática, post-procesado, videos y de la plataforma eStudy abriendo fórums de debate por grupos y a aprender a discretizar la documentación on-line.



Figura 4. Ejemplo de tarea: Comprender un texto, interpretar los conceptos en una imagen 3D y valorar mediante un programa de cálculo que estudie la solución arquitectónica (sección constructiva extraída de la revista Tectónica).

El tercer objetivo se alcanza a través de una autocorrección del ejercicio, comentarios sobre el porqué del ejercicio y su proyección en la realidad profesional y finalmente de la elaboración de una rúbrica en la cual se autoevalúan a la vez que reflexionan sobre su propio aprendizaje.

Los conceptos que se autoevalúan en esta rúbrica son de tres signos; un primero que refleja el acierto de la solución, un segundo sobre el propio entendimiento del ejercicio que se refleja en la autocorrección y el tercero sobre competencias transversales tales como capacidad de análisis y crítica (Fig.5).

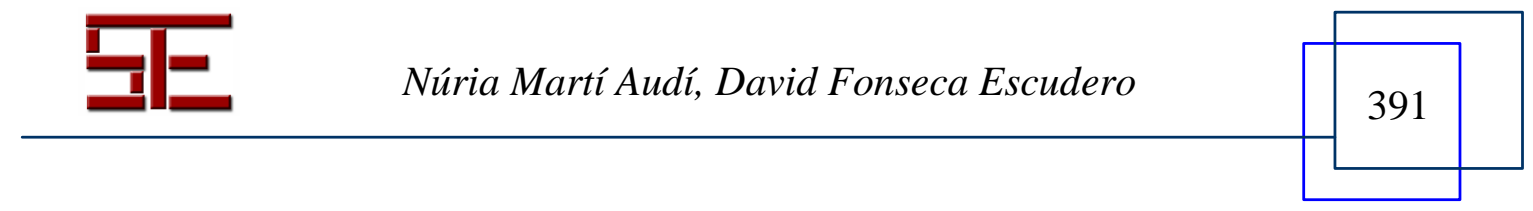




\begin{tabular}{ccc} 
Teoría de la Educación & Tducación y Cultura en la \\
$\begin{array}{c}\text { VNIVERSIDAD } \\
\text { DSALAMANCA }\end{array}$ & Sociedad de la Información & \\
\hline TESI, 14(2), 2013, pp. 376-402 &
\end{tabular}

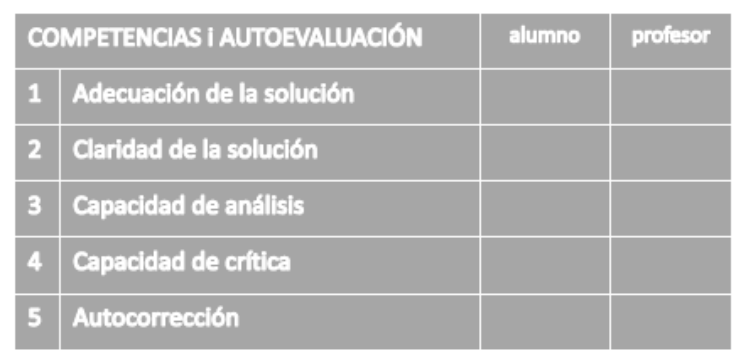

Figura 5. Rúbrica. Los alumnos se evalúan mediante varemos de intervalos sin llegar a ponerse una nota numérica

Para conseguir el triple objetivo las tareas siguen un formato establecido y están pautadas mediante tres fases: la primera y principal la propia tarea, la segunda la autocorrección y la tercera los comentarios y la rúbrica de autoevaluación.

Fases de la tarea:

El enunciado de la tarea se explica al finalizar la sesión teórica, relacionándola con la materia expuesta, y se da una semana, con fecha límite, para que se realice.

1. Fase: TAREA. Realizar el ejercicio, los comentarios de auto reflexión y subirlo a l'eStudy en .PDF y con el formato establecido.

2. Fase: AUTOCORRECCIÓN. Cerrado el término dado, el profesorado hace visible en la misma plataforma la solución y el alumno puede autocorregirse los errores, en formato papel, razonando por qué los han cometido.

En la clase presencial siguiente, el profesor resuelve las dudas que se hayan generado estableciendo una clase participativa que refuerza los conceptos teóricos. Los alumnos pueden terminar de autocorregir el ejercicio a la vez que realizar comentarios de las dificultades que se han encontrado.

3. Fase: AUTOEVALUACIÓN. Una vez resueltas todas dudas, los alumnos cumplimentan la rúbrica (Fig.5) al momento y vuelven a entregar la tarea. El profesor corrige la tarea, realiza la rúbrica y la retorna al alumno.

En estas tareas la plataforma eStudy se convierte en el medio de comunicación continuo y fluido se-mipresencial entre profesor y alumno.

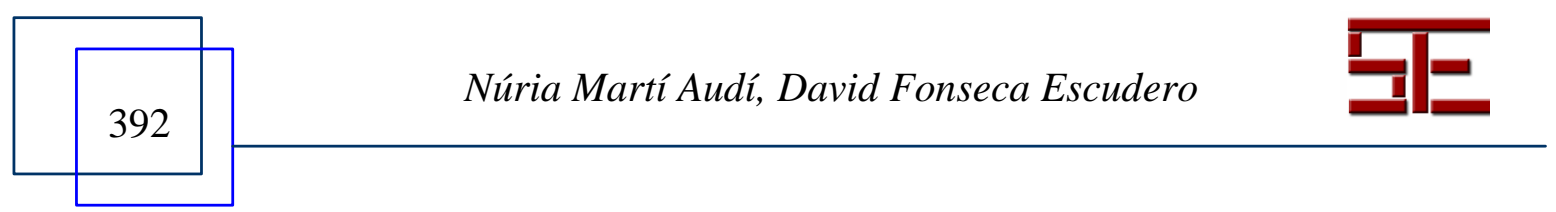




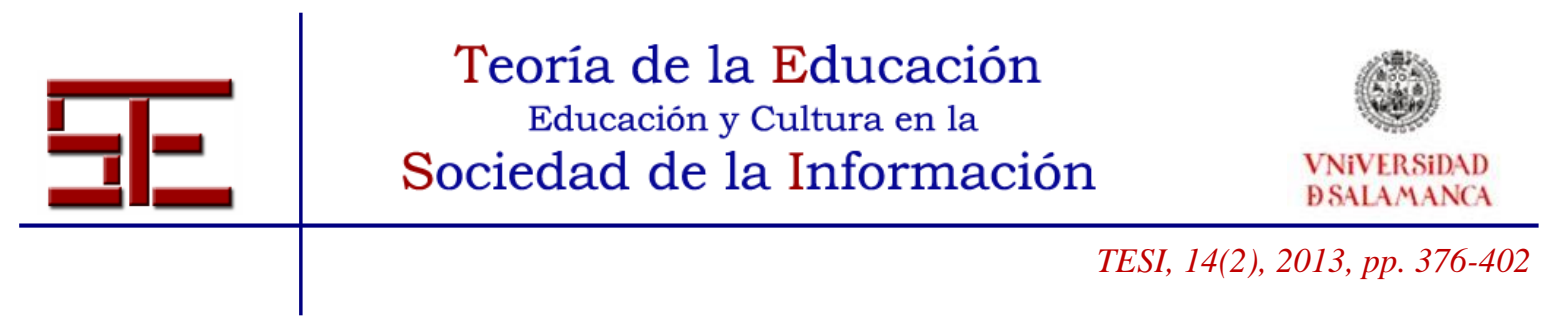

\section{3.- Jornadas de "Tecnología in situ".}

La estrategia de formación alterna actividades de carácter práctico y teórico en las que colaboran empresas, industriales y profesionales del sector de la construcción donde el alumno se especializa en distintos temas y se acerca su realidad profesional futura. En cada jornada se colabora con una empresa distinta y por lo tanto su método de trabajo, el sistema constructivo y su enfoque de mercado varía aportando al alumno diferentes puntos de vista.

Las jornadas de "tecnología in situ" son diversas y no siguen el ritmo programado de la asignatura a semejanza de un despacho de arquitectura que tiene que dar cabida a una visita de obra en un momento determinado. Por lo tanto, es una irrupción dentro del sistema reglado conscientemente previsto por tres motivos: crear puentes con la realidad profesional, crear pausas dentro de una estructura de ritmo de trabajo elevado y evitar la rutina, la pérdida de atención, reflexión y crítica.

La estructura de cada jornada se basa:

a. Puesta en obra.

b. Mesa redonda.

c. Tarea práctica.

\section{3.a- Puesta en obra. Ejecución.}

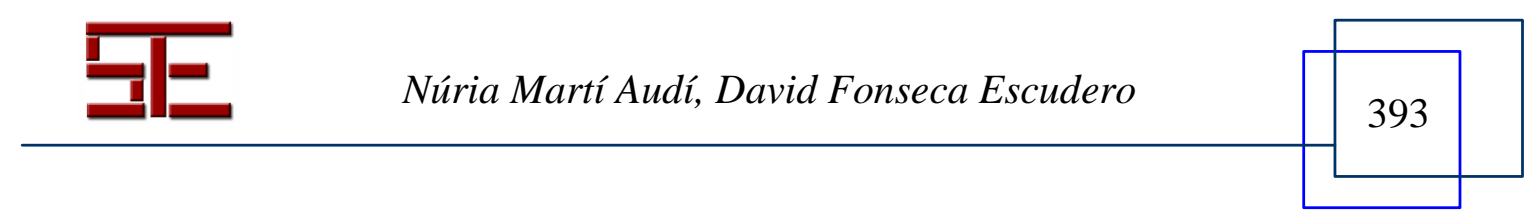




\begin{tabular}{c} 
Teoria de la Educación \\
Educación y Cultura en la \\
$\begin{array}{c}\text { VNiVERSDAD } \\
\text { BSALAMANCA }\end{array}$ \\
\hline TESI, 14(2), 2013, pp. 376-402
\end{tabular}

El primer estadio es totalmente práctico, se ejecuta la puesta en obra de distintos sistemas constructivos a escala real 1:1 frente a los alumnos (Fig.6).

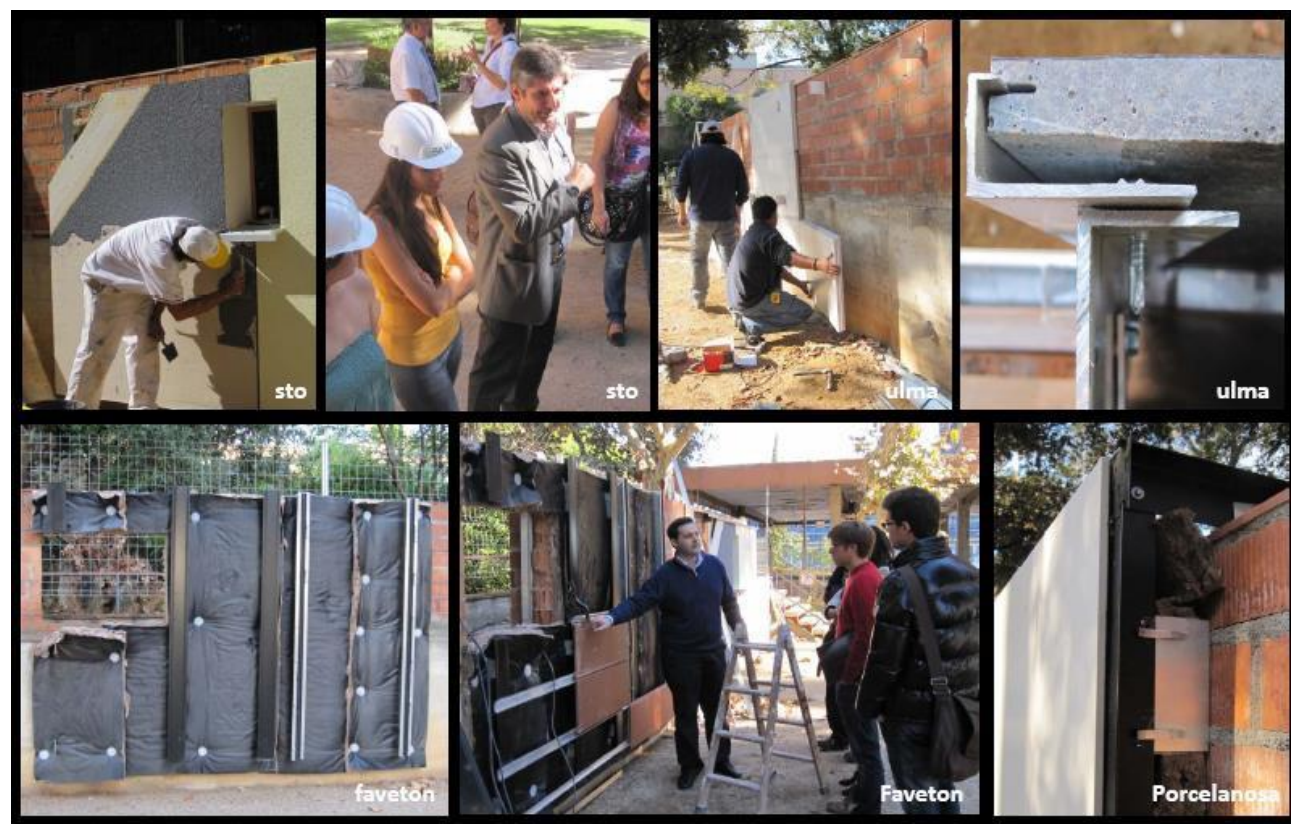

Figura 6. Puesta en obra de distintos sistemas constructivos de envolventes.

Los alumnos frente a la ejecución realizan croquis y detalles, fotografías, videos,..., y preguntan a los distintos personajes que intervienen en la ejecución dudas sobre del sistema, de sus características técnicas de su aplicabilidad, y a la vez sobre los conceptos abstractos de las sesiones de seminario.

\section{3.b.- Mesa redonda}

El segundo estadio es teórico-práctico en el cual se realizan conferencias y mesas redondas donde se debaten los distintos sistemas constructivos con los industriales, arquitectos y docentes. El hecho de concentrar estos tres perfiles permite tener argumentos divergentes ya que muchas veces la teoría, la práctica y la economía o el mercado no siguen los mismos criterios y por lo tanto ésta discusión constructiva aviva el entendimiento de los alumnos y hace evidente que hay distintas soluciones posibles para un mismo problema.

\section{3.c.- Tarea práctica}

El último estadio es una tarea práctica individual que interrelaciona la jornada de "tecnología in situ" con el conocimiento teórico de los seminarios. El trabajo tiene un

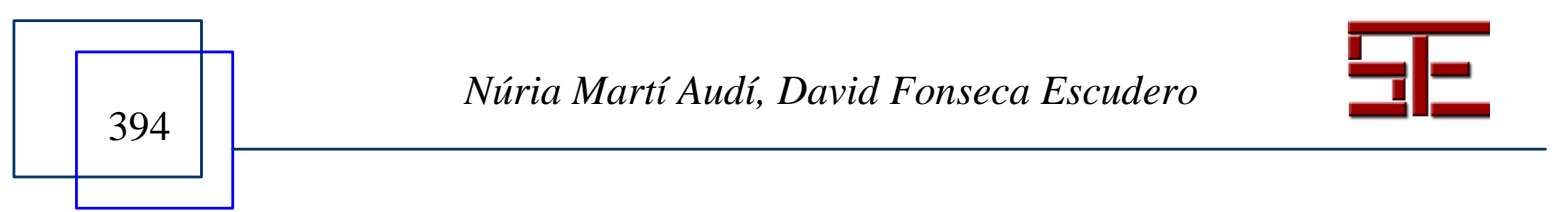




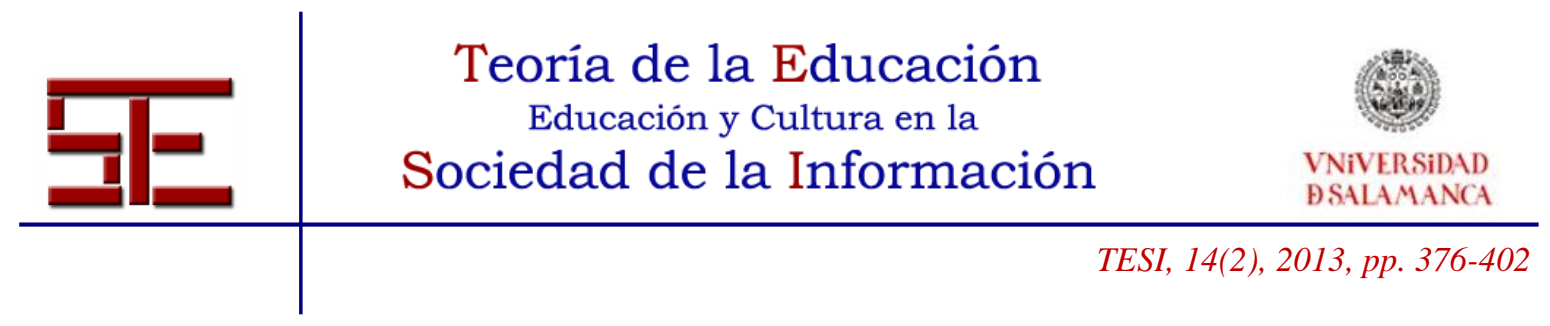

formato de presentación establecido recogiendo toda la experiencia mediante fotografías, dibujos 2D y 3D, textos y tablas que justifican y contrasta los conceptos teóricos de manera objetiva (Fig. 7).

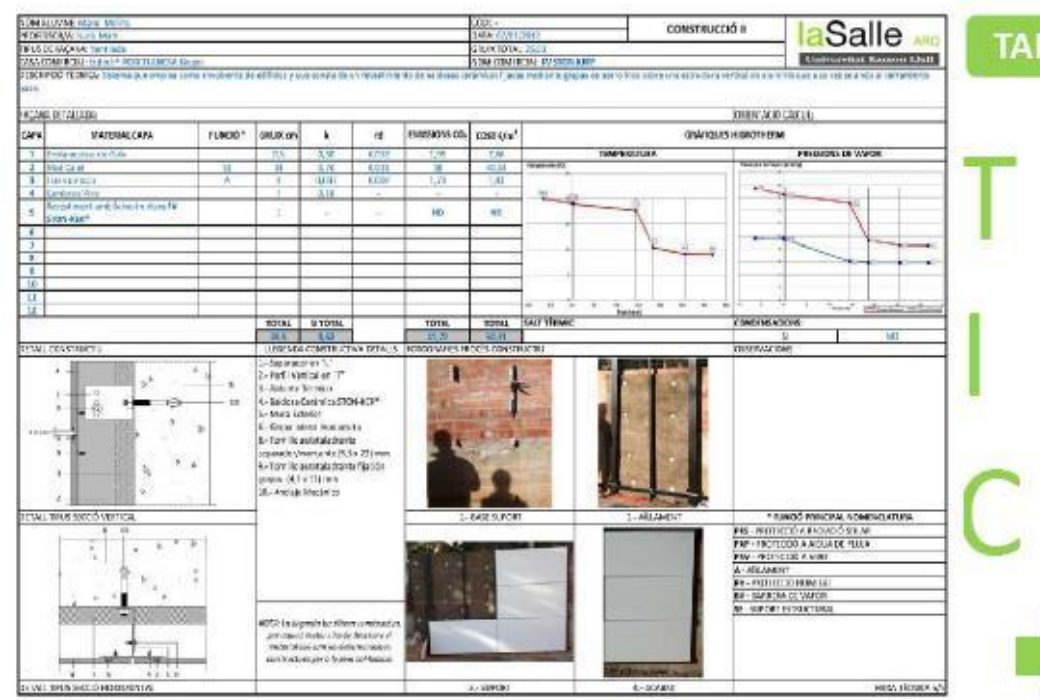

TAREAS TÉORICO-APRÁCTICAS

RESOLUCIÓN EJERCICIO

Figura 7.Tarea práctica que interrelaciona la jornada de "tecnología in situ" con los conceptos teóricos.

La entrega de la tarea se realiza a través de l'eStudy mediante documento .PDF con fecha límite, obligando a los alumnos que converjan en un único documento las tareas realizadas con los distintos programas informáticos.

Estos trabajos se consideran a la vez apuntes que los propios alumnos se elaboran, con la intención que aprendan a estructurar jerárquicamente según la relevancia los distintos conceptos teóricos. Considerándose como apuntes se eligen los mejores y se suben a l'eStudy como tales.

\section{4.- Laboratorios de tutoría y apuntes digitales e interactivos, web, blog.}

\subsection{1-Laboratorios de tutoría}

Los alumnos disponen de laboratorios de consulta de todas las asignaturas técnicas del grado: estructuras, instalaciones y construcción. En estas horas de tutoría presenciales se puede resolver cualquier duda planteada en cualquier asignatura y por lo tanto también, dudas de las tareas y del problema colaborativo de Construcción II.

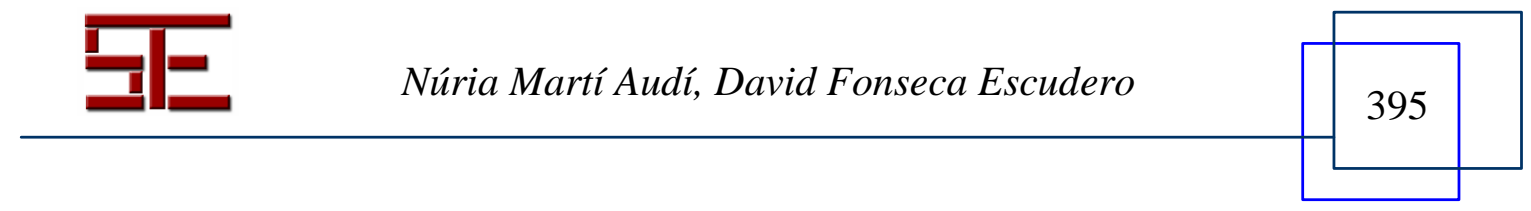




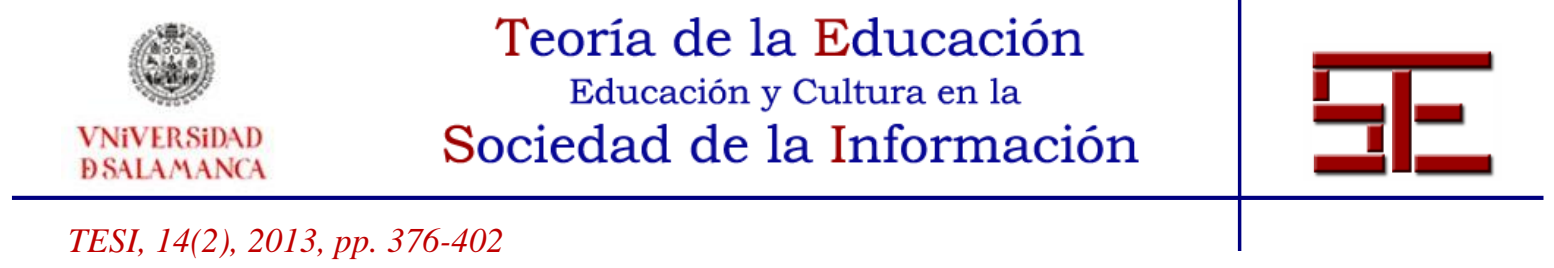

En este laboratorio coinciden las consultas de alumnos de todos los cursos, de manera que los alumnos de segundo coinciden con alumnos de los Talleres de segundo ciclo o del Proyecto Fin de Carrera proporcionándoles perspectivas diversas y más complejas, abriéndoles la mente a la vez que ven la continuidad de la enseñanza. Éste aspecto es el diferenciador del aprendizaje de las consultas que pueden realizar los alumnos de Construcción II a través de los foros de la asignatura.

\subsection{2.- Herramientas en línea. Apuntes digitales interactivos}

Los alumnos disponen de información de la asignatura a través de la plataforma del eStudy y una web abierta del Área de Construcción. La información se almacena, a manera de biblioteca digital, en distintos formatos de lectura y visualización: presentaciones, artículos, apuntes, videos, conferencias e imágenes incluyendo trabajos de alumnos de años pasados, entre otros.

También hay abierto un blog donde los alumnos pueden ir interactuando y donde los profesores anuncian distintas actividades relacionadas con el área que se están produciendo en el ámbito profesional.

Ahora bien, en la actualidad se están preparando unos apuntes digitales interactivos para facilitar el aprendizaje autónomo de los alumnos a través de una interfaz que les será más próxima, en parte al estar considerados como nativos digitales, que agrupa todo tipo de formatos en un único documento.

En la confección de estos apuntes colaboran estudiantes de años pasados aportando sus puntos de vistas en cuanto al diseño del formato, la estructura y contenido de los conocimientos y en cuanto a su usabilidad. Esta participación de alumnado nos permite realizar testeo de la eficacia de los apuntes para llegar a tener un iText eficaz.

Para dinamizar la lectura y el aprendizaje activo de los alumnos, los apuntes disponen de diversos aplicativos interactivos: como por ejemplo una galería de imágenes vinculadas a textos, videos y presentaciones y documentales con atributos. Asimismo, para conseguir profundizar en el aprendizaje autónomo se incorpora al final de los apuntes teóricos una parte práctica basada en ejercicios y test de repaso con soluciones activas y screencast.

Para generar los apuntes digitales se está usando el entorno operativo de Mac por las enormes posibilidades de los programas iText y el recurso de la plataforma de iTunes-u.

En la encuesta realizada a los alumnos se observa que, ya el $35 \%$ dispone de ordenador Mac, un $41 \%$ de un Iphone y un 14\% de un Ipad y el 20\% de los alumnos que no disponen de estos dispositivos próximamente adquirirán alguno de éstos dispositivos por lo tanto se considera un interface válida para seguir trabajando con élla.

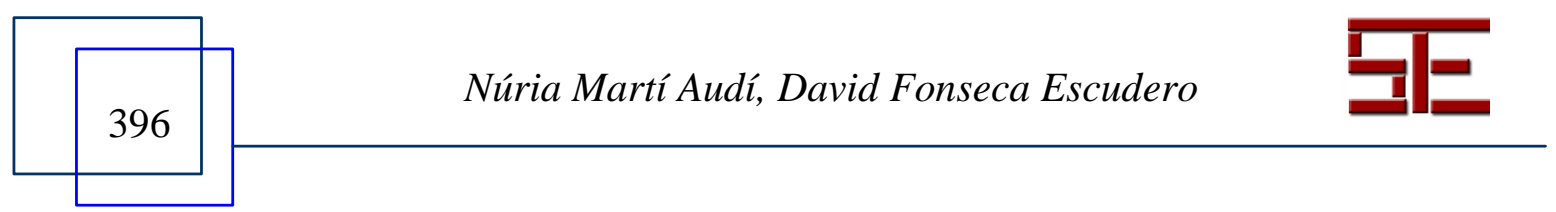




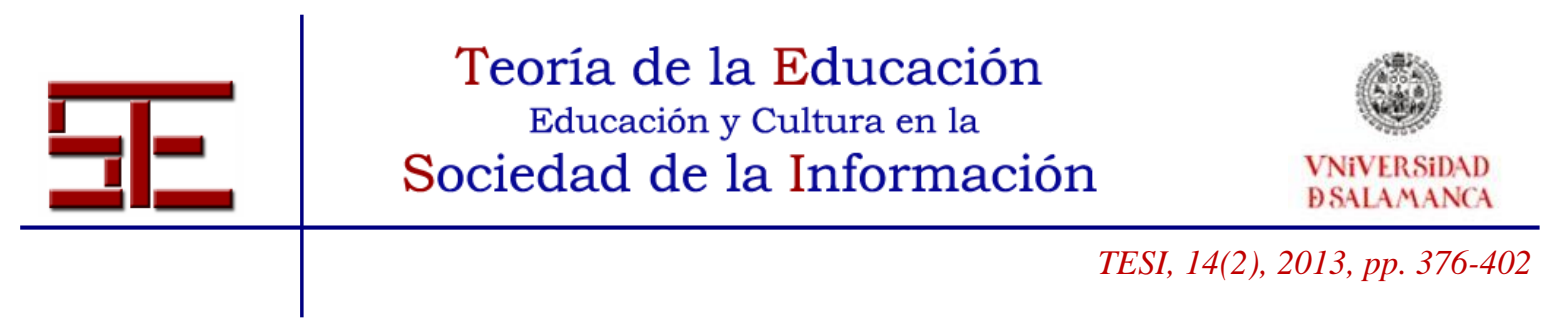

En el caso de los alumnos que no disponen de dispositivos de Mac, simultáneamente se están generando apuntes con formato de lectura .PDF y con la implementación de imágenes activas a través de QRmovie.

\section{5.- INTERRELACIÓN COLABORATIVA: VÍNCULO ENTRE UNIDADES DE APRENDIZAJE.}

Como hemos visto la relación entre las unidades de aprendizaje está estratégicamente diseñada. La estructura general que interrelaciona las distintas unidades sigue el procedimiento de aprendizaje por descubrimiento activo en el cual se plantea primero la problemática para esbozar las preguntas adecuadas, reflexionar, analizar y encaminar las soluciones apropiadas.

La planificación de todas las tareas está encadenada haciéndose necesarias todas ellas para completar el aprendizaje. Solamente las jornadas de "tecnología in situ" tienen su calendario autónomo al igual que en un despacho de arquitectura con las visitas de obra imprevistas.

El alumno es el responsable de relacionar los conceptos; siguiendo el ritmo de las distintas unidades a la vez que toda la documentación y comunicación a través del eStudy. Con este diseño el aprendizaje autónomo se produce de manera normal, tanto en habilidades como en saberes.

En toda estructura totalmente planificada estratégicamente las herramientas TIC forman parte inherente de la manera de trabajar y los alumnos la asumen de manera natural, convirtiéndose la plataforma del eStudy en un medio de comunicación continuo y fluido entre profesor y alumno.

\section{6.- CONCLUSIONES. VALORACIONES DE LA EXPERIENCIA.}

Los resultados del aprendizaje son muy favorables: la evaluación, según encuesta anónima realizada al alumnado el último día de clase de las distintas unidades supera la media de 6 sobre 10: un 6.70 con un 5\% de No Presentados (NP) en las tareas de seminario y "tecnología in situ” y un 6.58 con $9 \%$ de NP en el Taller 0 (Fig.8).

En cuanto al aprendizaje del alumnado, estos muestran tanto conocimientos teóricos como capacidad para analizar situaciones para su aplicabilidad y detectar algunos de los problemas a los que deberán dar solución a partir de sus conocimientos de construcción

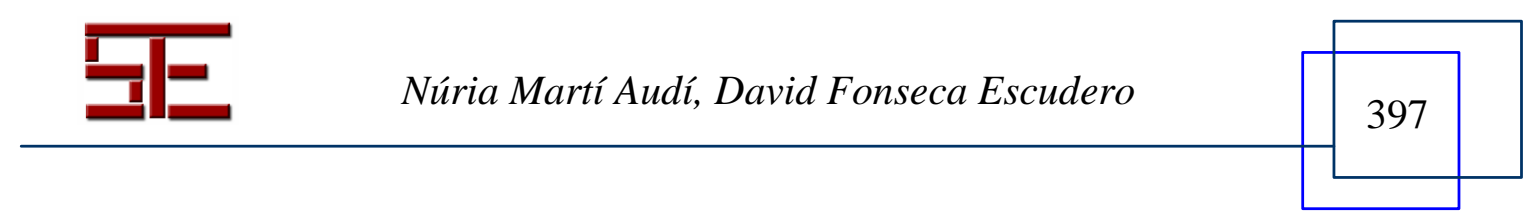




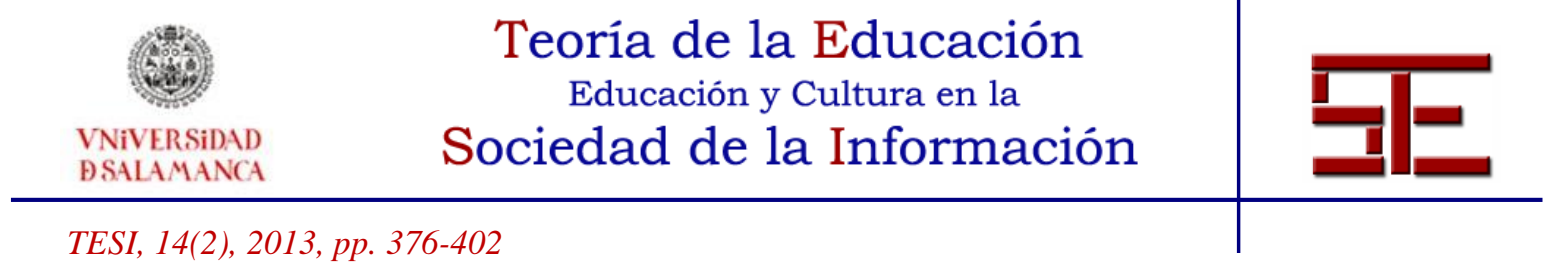

y del comportamiento de los materiales. Evidentemente estos conocimientos y habilidades requerirán de un trabajo de afianzamiento y ampliación a lo largo del resto de los cursos de Taller de Proyectos y como no, a lo largo de su vida profesional.

Ahora bien, la dedicación y el esfuerzo y necesidad de concentración es mucho mayor al aprendizaje tradicional y la empatía entre el alumno y el profesor es crucial, sin ella o bien hay abandono de aula o bien el conocimiento se convierte en duda e inseguridad. En este sentido la valoración hacia el profesorado, la podemos considerar muy positiva al situarse sobre un $4 / 5$, tanto en conocimientos, atención y claridad de la explicación. Es muy importante para el éxito de este formato el dimensionado preciso tanto de "la cantidad de conocimientos a impartir", como de todas las actividades que se generan en el proceso. La maduración de los conocimientos en el tiempo sigue siendo importante, incluso más desde el momento que se les exige reflexión, análisis y capacidad de síntesis.

\begin{tabular}{|l|l|}
\hline \multicolumn{2}{|c|}{ CONSTRUCCIÓN II. Curso 2011-12 } \\
\hline En conjunto el Contenión de las unidades de aprendizaje & Valor \\
\hline La materia puedes aplicarla a otras asignaturas & 4.2 \\
\hline PBL: es útlil para aprender la materia & 4.4 \\
\hline PBL: buscar la solución a priori de la teoria, ayuda a aprendrer. & 4.3 \\
\hline PBL: saber razonar me ayuda a aprender & 3.1 \\
\hline Tareas de Seminario: son utiles para aprender coneptos & 3.4 \\
\hline Pindolas del Seminario: son utiles para aprender coneptos & 3.8 \\
\hline Tecnologia in situ: la puesta en obra ayuda a asimilar conceptos. & 4.1 \\
\hline Tecnologia in situ: el debate ayuda a asimilar conceptos & 4.3 \\
\hline Apuntes: los he consultado & 3.7 \\
\hline
\end{tabular}

Figura 8. Encuesta realizada a un 64\% de los alumnos del curso (119 alumnos). Promedios de valores del 1 a 5 siendo 1: poco de acuerdo y 5: muy de acuerdo.

Actualmente, la metodología propuesta se ha replicado en el primer semestre del curso 2012-2013 en las asignaturas de Construcción I y Construcción II del grado de Arquitectura la Salle, estando en fase de análisis los datos obtenidos. Así mismo y como líneas de futuro más concretas, se están migrando los contenidos en apuntes digitales interactivos y se están diseñando toda una serie de exámenes digitales tipo test de

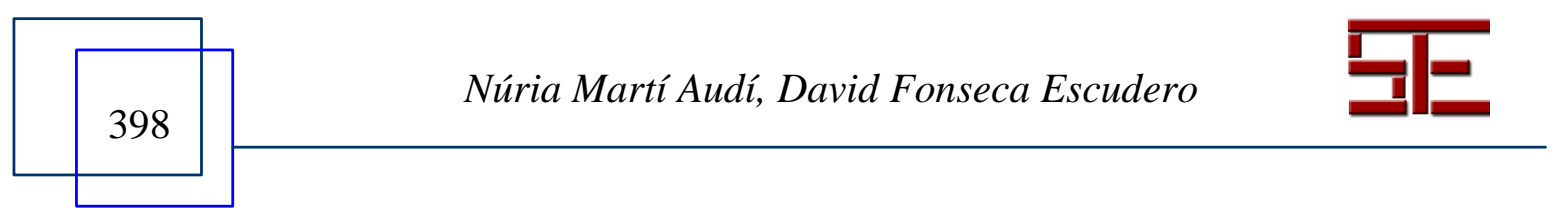




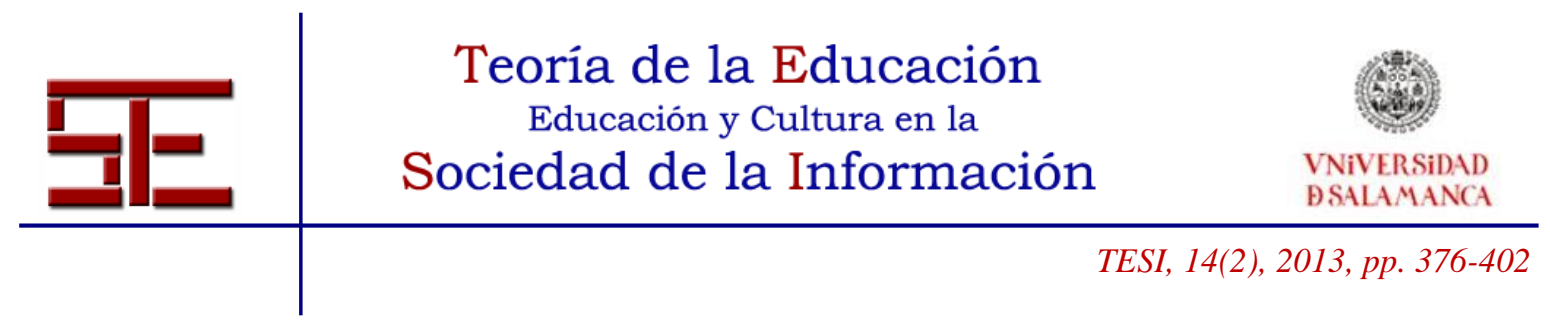

múltiples respuestas asociadas entre ellas para evaluar el grado de conocimiento de las diversas unidades de aprendizaje tratadas transversalmente a lo largo del curso.

\section{7.- BIBLIOGRAFÍA.}

Álvarez, I., Ayuste, A., Gros, B., Guerra, V., Romañá, T. (2005). Construir conocimiento con soporte tecnológico para un aprendizaje colaborativo. Revista Iberoamericana de Educación. Disponible en: http://www.rieoei.org/tec_edu37.htm [Consulta 04/09/08].

Área, M., San-Nicolás, M.B., Fariña, E. (2010). Buenas prácticas de aulas virtuales en la docencia universitaria semi-presencial. Teoría de la Educación. Educación y Cultura en la Sociedad de la Información, 11(3), pp.7-31.

Bates, A. W., Pole, G. (2003). Effective Teaching with Technology in Higher Education: Foundations for Success. Jossey-Bass Inc. U.S. 978-0-7879-6034-6. pp.336.

Barkley, E.F. (2007). Técnicas de aprendizaje colaborativo: manual para el profesorado universitario. Madrid. Morata. 236p.

Berggren, A., Burgos, D., Fontana, J.M., Hinkelman, D., Hung, V., Hursh, A., Tielemans, G. (2005). Practical and Pedagogical Issues for Teacher Adoption of IMS Learning Design Standards in Moodle LMS. JIME Special Issue: Advances in Learning Design.

Bouchlaghem, D., Shang, H., Whyte, J. Ganah, A., (2005). Visualisation in architecture, engineering and construction (AEC). International Journal of Automation in Construction, 14, pp.287-295.

Callaway, E., (2009). iTunes university' better than the real thing. Disponible en: http://www.newscientist.com/article/dn16624-itunes-university-better-than-thereal-thing.html [Consulta 15/02/2012].

Champeny, L., Borgman, C.L., Leazer, G.H., Gilliland-Swetland, A.J., Millwood, K.A., D’Avolio, L., Finley, J.R., Smart, L.J., Mautone, P.D., Mayer, R.E., Johnson. R.A. (2004). Developing a digital learning environment: an evaluation of design and implementation processes. In Proceedings of the 4th ACM/IEEE-CS joint conference on Digital libraries (JCDL '04). ACM, New York, NY, USA, 37-46. DOI=10.1145/996350.996361.

Coll, C., Palacios, J., Marchesi, A. (2004). Desarrollo psicológico y educación II. Psicología de la educación escolar. Madrid. Alianza. 720p.

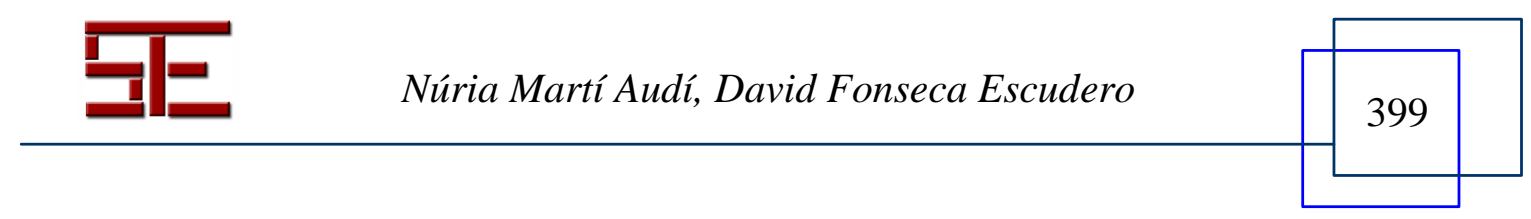






Collazos, C., Guerrero, L., Vergara, A. (2001). Aprendizaje colaborativo: un cambio en el rol del profesor. Memorias del III Congreso de Educación Superior en Computación, Jornadas Chilenas de la Computación. Punta Arenas, Chile.

Dougiamas, M., Taylor, P. (2003). Moodle: Using Learning Communities to Create an Open Source Course Management System. In D. Lassner \& C. McNaught (Eds.), Proceedings of World Conference on Educational Multimedia, Hypermedia and Telecommunications 2003). Chesapeake, VA: AACE. pp.171-178.

Fonseca, D., Redondo, E., Sánchez, A., Villagrasa, S., Martí, N. (2012). Visualization methods in architecture education using 3D virtual models and augmented reality in mobile and social networks. 3rd World Conference on Learning, Teaching \& Administration. 25-28 October 2012, Brussels, Belgium - Procedia-Social and Behavioral Sciences.

Font, A. (2004). Líneas maestras para el Aprendizaje por Problemas. Revista Interuniversitaria del Profesorado 18(1), 16.

García García-Cervigón, J., (2010). Reseña de "Innovación docente: Docencia y TICS". Teoría de la Educación. Educación y Cultura en la Sociedad de la Información, 11(1), pp. 444-445.

Georgina, D.A., Olson, M.R., (2007). Integration of technology in higher education: A review of faculty self-perceptions. Internet and Higher Education, 11. Pp.1-8. doi:10.1016/j.iheduc.2007.11.002.

Glick, S., Clevenger, C., Porter, D., (2011). Integrating 3D Models in Construction Management Education: Masonry Interactive Homework. 47th ASC Annual International Conference Proceedings, Associated Schools of Construction, Omaha, Nebraska, pp. 265-261.

Guiliarte Martín-Calero, C. (2008). Innovación docente: Docencia y TICS, Valladolid, Universidad de Valladolid, pp. 470.

$\mathrm{Hu}$, B.-Y. (2006). Book review: Integrating technology into higher. Educational Technology \& Society, 9(1), pp.359-360.

Jabi, W. (2003). Reflections on Computer-Supported Cooperative Design Systems. CAAD Futures 2003Proceedings, Kluwer Academic Publishers, Netherlands, pp. 169-180.

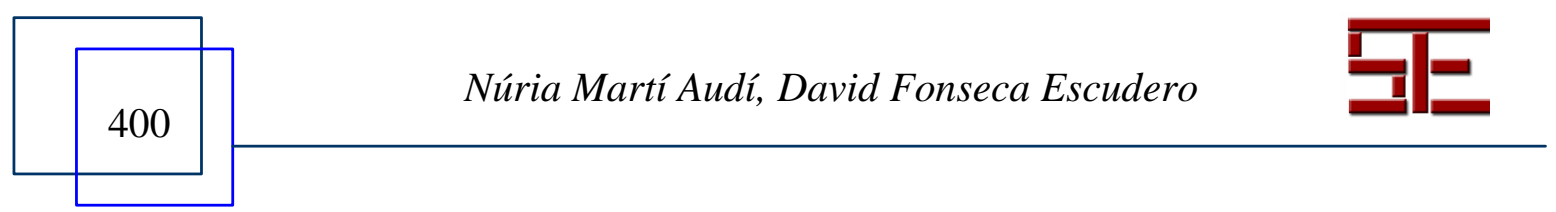




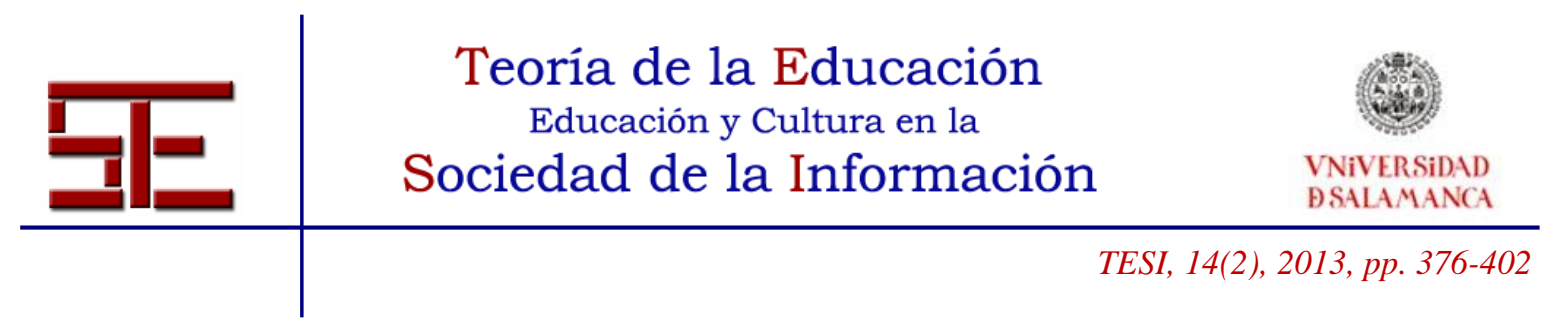

Kocaturk, T. (2010). A Web-Based teaching/learning environment to support collaborative knowledge construction in design. Journal of Information Technology in Construction. 15. pp.271-290.

Kondratova, I., Goldfarb, I., (2004). Knowledge portal as a new paradigm for scientific publishing and collaboration. Journal of Information Technology in Construction, 9, pp. 161.

Knox, E. (2007). MIT lecturers top the iTunes U top ten, News Office Correspondent, MIT news, Disponible en: http://web.mit.edu/newsoffice/2007/itunesu-lewin0725.html [Consulta: 15/02/2012].

Leopold, C., Górska, R.A., Sorby, S.A. (2001). International Experiences in Developing the Spatial Visualization Abilities of Engineering Students. Journal for Geometry and Graphics 5(1), pp.81-91.

Machado, M. (2007). Blackboard vs. moodle: Comparing user experience of learning management systems. 37th ASEE/IEEE Frontiers in Education Conference Milwaykee, USA.

Mareca, P., Bosch, V.A. (2011). Editing the Wikipedia: Its role in science education. In Proceedings of Information Systems and technologies (CISTI), $6^{\text {th }}$ Iberian Conference on, 1(1), pp.1-5.

Martens, B. and Turk, Z. (2003). Cumulative Index of CAAD: Current Status and Future Directions. International Journal of Architectural Computin, 1(2), pp. 220-231.

Martín-Gutiérrez, J., Gil, F. A., Contero, M., Saorín, J. L. (2010). Dynamic threedimensional illustrator for teaching descriptive geometry and training visualisation skills. Comput. Appl. Eng. Educ. Doi: 10.1002/cae.20447.

Milliken, J., Philip-Barnes, L., (2002). Teaching \& Technology in Higher Education: Student Perceptions and Personal Reflections. Journal of Computers in Education, 39(3), pp.223-235.

Nativos Digitales (2007). Niños y jóvenes frente a la tecnología: Internet, Videojuegos y móviles. Disponible en: http://www.nativos-digitales.net [Consulta 12/04/2012].

Nawari O. (2010), Intelligent design in AEC education. Journal of Information Technology in Construction, 15, pp. 306-317.

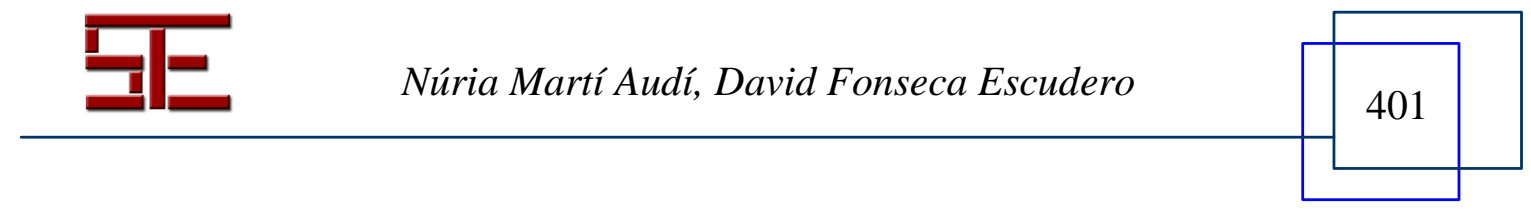




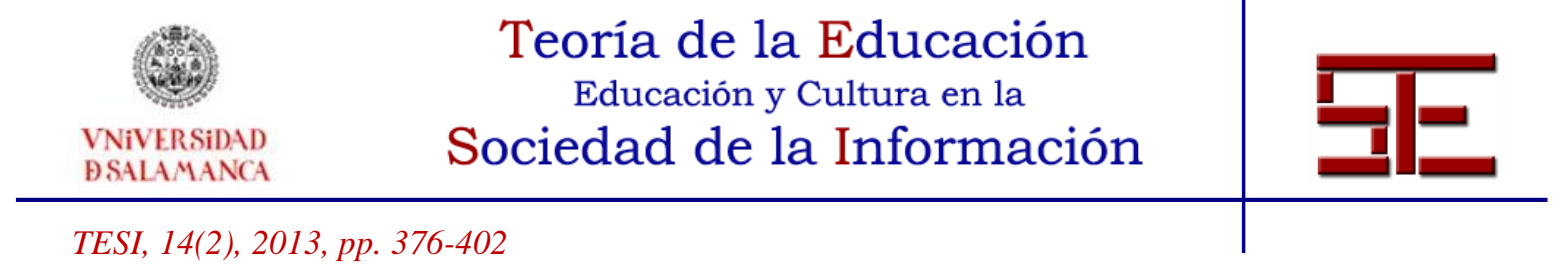

Ng, E. M. W. (2010). Extending learning to interacting with multiple participants in multiple Web 2.0 learning communities. Issues in Informing Science and Information Technology, 7, pp.11-23.

Pozo J.I., Monereo C. (1999). El aprendizaje estratégico. Aula XXI, Santillana, Madrid.

Prieto, C., Rodríguez, C., Hernández, A., Queiruga, A. (2011). Experiencias docentes de trabajo colaborativo en distintas áreas de ciencias. Teoría de la Educación. Educación y Cultura en la Sociedad de la Información, 12(4), pp.133-146.

Rodriguez-Izquierdo, R.M. (2010). El impacto de las TIC en la transformación de la enseñanza universitaria: repensar los modelos de enseñanza y aprendizaje. Teoría de la Educación. Educación y Cultura en la Sociedad de la Información, 11(3), pp.32-68.

Rogers, D. L. (2000). A paradigm shift: Technology integration for higher educa-tion in the new millennium. Educational Technology Review, 13, pp.19-27.

Unal, a., Unal, A., (2011). Evaluating and Comparing the Usability of Web-based Course Management Systems. Journal of Information Technology Education, 10, pp.19-38.

Valverde, J., Garrido, M.C., Fernández, R. (2010). Enseñar y aprender con tecnologías: un modelo teórico para las buenas prácticas con TIC. pp. 203-229.

Para citar el presente artículo puede utilizar la siguiente referencia:

Martí Audí, N. y Fonseca Escudero, D. (2013). Unidades de aprendizaje activas interrelacionadas con uso natural de herramientas TIC en la construcción arquitectónica. Revista Teoría de la Educación: Educación y Cultura en la Sociedad de la Información. 14(2), 376-402 [Fecha de consulta: dd/mm/aaaa].

http://campus.usal.es/ revistas_trabajo/index.php/revistatesi/article/view/10236/10669 